\title{
Estimation of the vertical profile of sulfur dioxide injection into the atmosphere by a volcanic eruption using satellite column measurements and inverse transport modeling
}

\author{
S. Eckhardt ${ }^{1}$, A. J. Prata ${ }^{1}$, P. Seibert ${ }^{2}$, K. Stebel ${ }^{1}$, and A. Stohl ${ }^{1}$ \\ ${ }^{1}$ Norwegian Institute for Air Research, Kjeller, Norway \\ ${ }^{2}$ Institute of Meteorology, University of Natural Resources and Applied Life Sciences, Vienna, Austria
}

Received: 21 January 2008 - Published in Atmos. Chem. Phys. Discuss.: 25 February 2008

Revised: 23 May 2008 - Accepted: 20 June 2008 - Published: 22 July 2008

\begin{abstract}
An analytical inversion method has been developed to estimate the vertical profile of $\mathrm{SO}_{2}$ emissions from volcanic eruptions. The method uses satellite-observed total $\mathrm{SO}_{2}$ columns and an atmospheric transport model (FLEXPART) to exploit the fact that winds change with altitude - thus, the position and shape of the volcanic plume bear information on its emission altitude. The method finds the vertical emission distribution which minimizes the total difference between simulated and observed $\mathrm{SO}_{2}$ columns while also considering a priori information. We have tested the method with the eruption of Jebel at Tair, Yemen, on 30 September 2007 for which a comprehensive observational data set from various satellite instruments (AIRS, OMI, SEVIRI, CALIPSO) is available. Using satellite data from the first $24 \mathrm{~h}$ after the eruption for the inversion, we found an emission maximum near $16 \mathrm{~km}$ above sea level (a.s.l.), and secondary maxima near 5, 9,12 and $14 \mathrm{~km}$ a.s.l. $60 \%$ of the emission occurred above the tropopause. The emission profile obtained in the inversion was then used to simulate the transport of the plume over the following week. The modeled plume agrees very well with $\mathrm{SO}_{2}$ total columns observed by OMI, and its altitude agrees with CALIPSO aerosol observations to within $1-2 \mathrm{~km}$. The inversion result is robust against various changes in both the a priori and the observations. Even when using only SEVIRI data from the first $15 \mathrm{~h}$ after the eruption, the emission profile was reasonably well estimated. The method is computationally very fast. It is therefore suitable for implementation within an operational environment, such as the Volcanic Ash Advisory Centers, to
\end{abstract}

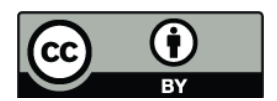

Correspondence to: A. Stohl (ast@nilu.no) predict the threat posed by volcanic ash for air traffic. It could also be helpful for assessing the sulfur input into the stratosphere, be it in the context of volcanic processes or also for proposed geo-engineering techniques to counteract global warming.

\section{Introduction}

Volcanic eruptions release gases (e.g., water vapor, carbon dioxide, sulfur dioxide, hydrogen sulfide, hydrogen chloride) and solid matter into the atmosphere (Robock and Oppenheimer, 2004). Solid matter contained in eruptions comprises a wide range from solidified pieces of lava with masses of many kilogrammes down to fine particles in the submicron range. While large objects fall back to the surface close to the volcano, fine silicate particles, usually referred to as volcanic ash, can remain in the atmosphere for many days.

The injection height of both gases and ash into the atmosphere varies substantially.

For passive degassing, the injection height is on the order of hundreds of meters and is dominated by thermal plume rise, whereas explosive eruptions have a substantial initial exit velocity. The volcanic plume height also depends critically on the ambient atmospheric conditions (Oberhuber et al., 1998), in particular on the thermal stratification, humidity and wind profile. According to Halmer and Schmincke (2003), $80 \%$ of the plumes from explosive volcanic eruptions rise higher than $6 \mathrm{~km}, 60 \%$ higher than $10 \mathrm{~km}$, and $20 \%$ higher than $15 \mathrm{~km}$. Material from very strong explosive eruptions such as the Pinatubo eruption in 1991 can reach altitudes of more than $30 \mathrm{~km}$ (McCormick et al., 1995).

Published by Copernicus Publications on behalf of the European Geosciences Union. 
Climatic effects of volcanic eruptions are dominated by sulfur dioxide $\left(\mathrm{SO}_{2}\right)$ emissions, as $\mathrm{SO}_{2}$ is converted to sulfate particles which scatter sunlight and increase the Earth's albedo (Textor et al., 2003). They are removed from the troposphere by wet deposition within a few days, however, their lifetime in the stratosphere ranges from months to years. Stratospheric sulfate cools the troposphere (McCormick et al., 1995) and influences the atmospheric circulation (Graf et al., 2007).

Volcanic ash, on the other hand, is a serious danger to jet aircraft. Ingestion into jet engines can cause damage and even engine failure. Therefore, Volcanic Ash Advisory Centers (VAAC), designated by the World Meteorological Organisation (WMO), issue warnings about ash clouds at flight altitudes that may lead to re-routing of air traffic. These warnings are based on initial eruption reports, air crew sightings, satellite data, and atmosperic transport modeling. The latter requires an assumption on the source term and especially its vertical profile. A standard assumption is a homogeneous distribution between the volcano's height and $12 \mathrm{~km}$ (Stunder et al., 2007), or a fitted ad hoc profile to match observations (Heffter, 1996).

Unfortunately, determining the vertical emission distribution of a volcanic plume is a challenge. In principle, it can be obtained from a high-resolution prognostic eruptioncolumn model such as the Active Tracer High Resolution Model (ATHAM), which uses the mass flux of pyroclastic material and the ambient meteorological conditions as boundary conditions (Oberhuber et al., 1998; Textor et al., 2003). However, getting appropriate input data to these models can be problematic, especially in real time when little information on the pyroclastic mass flux and other details of the eruption are available. Depths of volcanic ash columns are often estimated by local observers but this is of unknown accuracy and many volcanic eruptions in remote areas are not observed by eye-witnesses at all. Furthermore, plumes containing $\mathrm{SO}_{2}$ but no ash cannot be seen directly (accompanying cloud features may be visible). The plume height can also be determined using aircraft (Mankin et al., 1992) or ground-based weather radar or lidar (Wang et al., 2008) but such observations are often not available. Satellite instruments, in principle, provide global coverage. The CALIOP (Cloud-Aerosol Lidar with Orthogonal Polarization) lidar on board of the CALIPSO (Cloud-Aerosol Lidar and Infrared Pathfinder Satellite Observations) platform delivers global aerosol information. The vertical resolution, with $60 \mathrm{~m}$ (Winker et al., 2007) is high, but the horizontal sampling is poor, as the satellite is in an orbit with a 16day repeated cycle Vertical resolution is $30-300 \mathrm{~m}$. Horizontal resolution is $330 \mathrm{~m}$ to $5 \mathrm{~km}$. Scanning thermal infrared sounders such as IASI (Infrared Atmospheric Sounding Interferometer) can provide some information on the vertical distribution of $\mathrm{SO}_{2}$ in a volcanic plume but at very coarse resolution (IASI has a horizontal resolution of $12 \mathrm{~km}$ (pixel size) and the vertical resolution depends on the information content of the retrieval. For $\mathrm{SO}_{2}$ it is about $1-2 \mathrm{~km}$.) (Clerbaux et al., 2007).

Most other satellite products (e.g., $\mathrm{SO}_{2}$ retrievals from SEVIRI (Second Generation Spin-stabilised Enhanced Visible and Infra-Red Imager), AIRS (Atmospheric Infra-Red Sounder) or OMI (Ozone Monitoring Instrument), see below) have no or little vertical resolution.

In this paper, we derive the vertical emission profile from atmospheric transport patterns as observed from space by platforms delivering column information but no vertical resolution.

It is generally acknowledged that ash is the primary volcanic hazard to aviation at cruise altitudes (e.g., Miller and Casadevall, 2000). Explosive eruptions, involving hot, viscous magma, have sufficient thermal energy to bring volcanic debris up to aircraft cruising altitudes or higher. These explosive eruption events are also gas-rich and contain copious amounts of $\mathrm{H}_{2} \mathrm{O}, \mathrm{CO}_{2}$ and $\mathrm{SO}_{2}$. In a sheared atmosphere the ash and $\mathrm{SO}_{2}$ in these eruption clouds may travel in different horizontal directions, but the $\mathrm{SO}_{2}$ is likely to reach higher altitudes, be accompanied by some ash and remain in the atmosphere for a longer time. The motivation for using $\mathrm{SO}_{2}$ as a tracer for hazardous volcanic clouds derives from two observations: It is critical to have accurate information on the altitude reached by volcanic debris, and $\mathrm{SO}_{2}$ is often more easily observed by satellite sensors than ash and has a greater atmospheric residence time.

At this stage, we consider only $\mathrm{SO}_{2}$, which is easier to retrieve than volcanic ash. This is important for geochemical and climate modeling in itself, and it may also serve VAACs as a proxy for volcanic ash. If the wind speed and/or direction changes with height in the atmosphere, and usually it does, the transport pattern derived from satellite imagery can be used to infer the initial emission profile. We do this by calculating transport from many height intervals in the supposed eruption column. By applying an inverse modeling framework, we find the emission profile which leads to simulated spatial patterns of $\mathrm{SO}_{2}$ column values matching best the observed ones over some assimilation time window. We explore this method in some detail for the recent eruption of Jebel at Tair, Yemen.

\section{The eruption of Jebel at Tair}

Jebel at Tair is a stratovolcano-a steep-sloped cone composed of alternating layers of ash, lava, and rocks produced by earlier eruptions. It is a roughly $4-\mathrm{km}^{2}$ island near the mouth of the Red Sea $\left(15.5^{\circ} \mathrm{N}, 41.8^{\circ} \mathrm{E}\right)$, with a crater summit presently $240 \mathrm{~m}$ a.s.l. but more than $1500 \mathrm{~m}$ above the sea floor (see http://en.wikipedia.org/wiki/Jabal_al-Tair_Island). Explosive eruptions were recorded in the past but for the last 124 years the volcano lay dormant. It erupted again in the afternoon of 30 September 2007 (BGVN, 2007) (see also http://earthfromspace.photoglobe.info/spc_jebel_al_tair. 
html). Several people died in a Yemeni military base on the island. Photographic evidence exists that a deep cloud formed above the volcano but we are not aware of any estimates of the height of this cloud.

There is little reliable information on the exact time of the eruption at Jebel at Tair. The most reputable source of information is the Bulletin of the Global Volcanism Network (BGVN). The October 2007 report (BGVN, 2007) provides a synopsis of information garnered from scientists, "eyewitness" accounts, news reports and historical records of Jebel at Tair. From this information the exact time of eruption cannot be ascertained but it occurred before 12:30 UT (15:30 local time (LT); $\mathrm{LT}=\mathrm{UT}+3)$. Since the eruption did reach high into the atmosphere $(\approx 16 \mathrm{~km}$ as inferred from the IASI retrieval and SEVIRI $12 \mu \mathrm{m}$ imagery: see next) and significant amounts of $\mathrm{SO}_{2}(50-100 \mathrm{kt})$ were injected it is likely that the eruption was energetic and possibly phreatomagmatic with initial vertical velocities of $50 \mathrm{~ms}^{-1}$ or more (Carey and Bursik, 2000).

We have used SEVIRI satellite imagery (12 $\mu \mathrm{m}$ channel) to look for indications of the onset time of the eruption. Figure 1 shows the time evolution of the pixel with the smallest value of the $12 \mu \mathrm{m}$ brightness temperature, which provides a very good indicator of cloud, within a small region centered over the volcanic island. The difference between 10.8 and $12 \mu \mathrm{m}$ temperatures which is often a very good indicator of cloudiness or anomalies in an image is also shown. The $12 \mu \mathrm{m}$ temperature drops rapidly after 11:27 UT, when a small cloud is noticeable in the imagery. Temperatures continue to drop reaching values around $195 \mathrm{~K}$ at 12:12 UT and then staying close to this value afterwards. The behavior of the temperature record suggests that the initial eruption (there may have been several eruptions) occurred not later than 11:27 UT and that the cloud reached neutral buoyancy between 12:00-12:30 UT. The temperature difference record shows a negative anomaly in the 11:57 UT image. This is often associated with the presence of volcanic ash but in this case is more likely indicative of overshooting and stratospheric penetration as very little ash was observed in any of the infrared or visible satellite imagery from this eruption. Later, the temperature difference rises and becomes strongly positive which is an indication of ice particles in the cloud. The minimum value of the $12 \mu \mathrm{m}$ brightness temperature is $192.6 \mathrm{~K}$ at $12: 57 \mathrm{UT}$. Figure 2 shows the ECMWF temperature profile at the nearest grid point $\left(16^{\circ} \mathrm{N}\right.$ and $\left.42^{\circ} \mathrm{E}\right)$ to the volcano, as well as a radiosonde temperature profile obtained from Abha, Saudi Arabia (for location, see Fig. $3,18.23^{\circ} \mathrm{N}, 42.65^{\circ} \mathrm{E}, 2084 \mathrm{~m}$ a.s.1.) The measurements from the radiosonde are very similar to the ECMWF vertical profile. For an opaque cloud, a temperature of $192.6 \mathrm{~K}$ corresponds to either 16.5 or $17.1 \mathrm{~km}$ a.s.l., just below or above the cold point in the ECMWF temperature profile $(192.1 \mathrm{~K}$ at $16.9 \mathrm{~km}$ ). This indicates that the cloud penetrated the thermal tropopause, found at an altitude of $15.3 \mathrm{~km}$ in the ECMWF

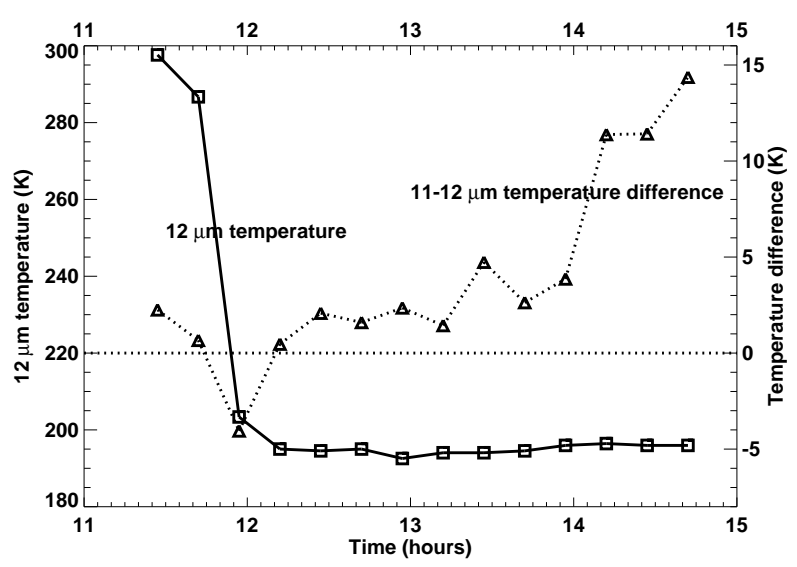

Fig. 1. Temporal evolution of the minimum $12 \mu \mathrm{m}$ SEVIRI brightness temperature (solid line) for the Jebel at Tair eruption cloud. Also shown is the $11-12 \mu \mathrm{m}$ brightness temperature difference (dashed line).

profile using the WMO standard definition. ${ }^{1}$

The tropopause in the Abha radiosounding is only slightly higher $(15.8 \mathrm{~km})$. One hour earlier, at 11:57 UT, the $12 \mu \mathrm{m}$ temperature is $203.4 \mathrm{~K}\left(-70^{\circ} \mathrm{C}\right)$, which suggests cloud top heights of either $19.1 \mathrm{~km}$ or $14.4 \mathrm{~km}$. The latter height seems more likely and hence we conclude that at this time the cloud was still undergoing vertical development.

In summary, the satellite observations combined with ECMWF and radiosonde temperature profiles suggest an initial eruption time no later than 11:27 UT, that the plume reached neutral buoyancy no earlier than 12:00 UT, had the minimum value of the $12 \mu \mathrm{m}$ brightness temperature at 12:57 UT and that it reached a height of more than $16 \mathrm{~km}$. It is probable that $\mathrm{SO}_{2}$ emissions continued at a reduced rate, either in the form of smaller eruptions or by effusive activity. However, for the inverse modeling, we assume that the $\mathrm{SO}_{2}$ observed by the satellites was all emitted during one explosive eruption.

\section{Satellite data}

The eruption of Jebel at Tair occurred in the mid-afternoon of a cloud-free day. Several satellite-borne instruments were able to acquire data for this eruption. Of particular relevance to this study was the availability of very high temporal resolution imagery from the geosynchronous Meteosat SEVIRI. Data from AIRS and OMI were also utilized. CALIPSO was able to detect the thin veil of sulfuric acid aerosol formed from the $\mathrm{SO}_{2}$ erupted from Jebel at Tair. Measurements from the Microwave Limb Sounder (MLS), the Infrared

\footnotetext{
${ }^{1}$ The tropopause is the lowest level at which the lapse rate decreases to $2{ }^{\circ} \mathrm{C} / \mathrm{km}$ or less, provided that the average lapse rate between this level and all higher levels within $2 \mathrm{~km}$ does not exceed $2{ }^{\circ} \mathrm{C} / \mathrm{km}$.
} 


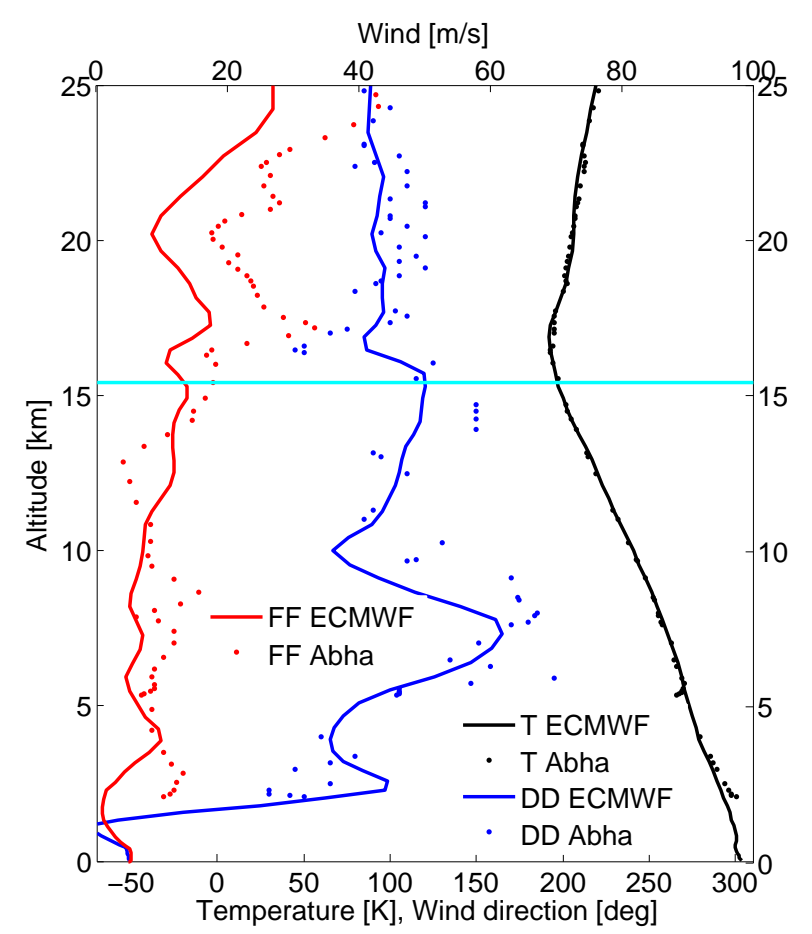

Fig. 2. Temperature, windspeed and winddirection as a function of altitude at 12:00 UT on 30 September 2007. The tropopause diagnosed from ECMWF data according to the WMO definition is located at $15.3 \mathrm{~km}$, (turquoise line). The dots show the temperature, wind speed (FF) and wind direction (DD) as measured by a radiosounding at Abha. The lines indicate the same parameters but taken from the ECMWF model.

Atmospheric Sounding Interferometer (IASI) and the second Global Ozone Monitoring Experiment (GOME-2) were also available but we have not made use of these data.

\subsection{OMI}

OMI is an ultra-violet (UV) imaging spectrometer designed principally for measuring global ozone (columns and profiles) but with secondary goals of measuring other trace gases, including $\mathrm{SO}_{2}$. It measures solar back-scattered radiation in the UV between 270 and $365 \mathrm{~nm}$. OMI is on board the polar orbiting EOS-Aura platform, is part of the A-train (NASA, 2003) and its (daytime) equator crossing time is 10:45 UT. The nadir pixel size is $13 \mathrm{~km} \times 24 \mathrm{~km}$ and the swath width is $2600 \mathrm{~km}$ which provides once-daily global coverage. $\mathrm{SO}_{2}$ column abundance is retrieved at $\mathrm{UV}$ wavelengths that have been optimised for $\mathrm{SO}_{2}$ detection and the Band Residual Difference (BRD) algorithm utilised takes account of the effects of ozone, surface reflectivity, Rayleigh multiple scattering, the "Ring effect" and the geometrical air-mass factor. The retrieval schemes used to determine column $\mathrm{SO}_{2}$ are described by Krotkov et al. (2006) and Yang et al. (2007) while use of $\mathrm{OMI} \mathrm{SO}_{2}$ data in volcanological applications can be found in the papers by Carn et al. (2007a) and Carn et al. (2007b). The $\mathrm{OMI} \mathrm{SO}_{2}$ retrievals have a standard deviation of \pm 0.5 Dobson Units (DU; $1 \mathrm{DU}=2.69 \times 10^{16}$ molecules $\mathrm{cm}^{-2}$ ) or less (Krotkov et al., 2006) but there is also a variable bias error of $0.2-0.5 \mathrm{DU}$, which depends on the reflectivity of meteorological clouds.

OMI SO 2 level 2 data products (OMSO2 V002) are available to the research community from the Distributed Active Archive Center (DAAC) maintained by NASA's Goddard Space Flight Center (GSFC) and were used in our analyses. Although $0.25^{\circ}$ resolution data are available, we chose to use the swath product and re-sample these data to a common grid. The data were resampled to a grid of $0.3^{\circ}$ longitude by $0.3^{\circ}$ latitude, within a rectangular box with coordinates: $20.15^{\circ} \mathrm{E}, 10.15^{\circ} \mathrm{N}, 100.85^{\circ} \mathrm{E}, 51.85^{\circ} \mathrm{N}$. Re-sampling was done using an efficient triangulation method and a smooth polynomial interpolation scheme.

\subsection{SEVIRI}

SEVIRI is an advanced geosynchronous imaging instrument with 12 channels measuring from the visible to the infrared region. At nadir the instantaneous field of view (IFOV) covers approximately $10 \mathrm{~km}^{2}$, while towards the limb the IFOV size increases. The instrument can complete an entire scan of $70^{\circ}$ of the Earth in $15 \mathrm{~min}$. Data were obtained via the on-line ordering system (U-MARF, Unified Meteorological Archive and Retrieval Facility) operated by Eumetsat ${ }^{2}$.

The SEVIRI data were obtained at 15 min time resolution, starting at 10:12:42 UT on 30 September 2007 and ending at 23:57:42 UT on 1 October 2007 for a large geographical region covering the Red Sea, Egypt and Saudi Arabia. The same re-sampling method used for OMI was used with the SEVIRI data to provide $0.3^{\circ} \times 0.3^{\circ}$ gridded data. For input into the inversion scheme, data were averaged to hourly values.

Not all of the SEVIRI measurements are useful for determining $\mathrm{SO}_{2}$ concentrations and we use the retrieval scheme developed by Prata and Kerkmann (2007) which relies only on the infrared measurements made at $6.2,7.3$ and $12 \mu \mathrm{m}$. The scheme makes use of the strong anti-symmetric stretch absorption feature of $\mathrm{SO}_{2}$ centered near $7.34 \mu \mathrm{m}$. For sufficiently large $\mathrm{SO}_{2}$ gas concentrations that lie above boundary layer water vapor, the top-of-the-atmosphere brightness temperature will be lowered compared to an atmosphere with no $\mathrm{SO}_{2}$ gas. The decrease in brightness temperature depends on a variety of factors, including the amount of gas, its height in the atmosphere and the presence of interfering gases (water vapor) and clouds. During the first $48 \mathrm{~h}$ of the Jebel at Tair eruption the skies were almost cloud-free and the atmosphere relatively dry. Since the gas cloud seems to have reached

\footnotetext{
${ }^{2}$ Details of the data formats and U-MARF can be found in various Eumetsat Technical Memoranda available from: http://www. eumetsat.int, under "Publications"
} 
$16 \mathrm{~km}$, water vapor effects are minimal and do not contribute a significant error to the retrieval. The retrieval method uses a look-up table based on off-line correlated-k radiative transfer calculations (Prata et al., 2003) to relate the band-averaged transmittance (for the SEVIRI channel centered at $7.3 \mu \mathrm{m}$ ) to $\mathrm{SO}_{2}$ columns. The SEVIRI retrieval scheme assumed the $\mathrm{SO}_{2}$ had reached a height of $16 \mathrm{~km}$. The estimated accuracy for a single IFOV is $\pm 6 \mathrm{DU}$.

The precision is difficult to ascertain because the major cause of interference is due to water vapor and this is not estimated during the retrieval process. However, for the cases where the $\mathrm{SO}_{2}$ is sufficiently high in the atmosphere (above $6 \mathrm{~km}$ ), the precision depends mostly on instrument noise, on the veracity of the off-line radiative transfer and the opacity of the $\mathrm{SO}_{2}$ gas cloud. We estimate the precision to be about $\pm 6 \mathrm{DU}$.

\subsection{AIRS}

AIRS is a high resolution grating spectrometer operating at infrared wavelengths between 3.7 and $15.4 \mu \mathrm{m}$ (Chahine et al., 2006) and is housed on the EOS-Aqua polar orbiting satellite with equator crossing times of 10:30 UT and 22:30 UT. AIRS scans a swath of $\pm 49^{\circ}$ from nadir with an IFOV of $1.1^{\circ}$ providing nadir pixels with dimensions $15 \times 15 \mathrm{~km}^{2}$, increasing to $18 \times 40 \mathrm{~km}^{2}$ at the swath edge. Level 1b AIRS products (L1B-AIRS-IR-Rad-V005) were obtained via anonymous ftp from the GSFC DAAC. These data are supplied as granules of 90 pixels by 135 lines and were re-sampled to the same grid as the OMI and SEVIRI data. The first Aqua overpass at 23:47 UT on 30 September 2007, some $12 \mathrm{~h}$ after eruption onset, imaged an incomplete cloud because the AIRS swath was insufficiently wide. However, the following day and up until 3 October, AIRS was able to provide good coverage of the $\mathrm{SO}_{2}$ cloud.

Like SEVIRI, AIRS has channels that cover the $7.3 \mu \mathrm{m}$ $\mathrm{SO}_{2}$ absorption feature, but at much greater spectral resolution (more than 100 channels). The $\mathrm{SO}_{2}$ retrieval scheme developed by Prata and Bernardo (2007) was used to determine column abundances. As for the SEVIRI retrieval, it was assumed that the $\mathrm{SO}_{2}$ had reached an altitude of $16 \mathrm{~km}$. This scheme takes advantage of the high spectral resolution and has a better accuracy and precision than SEVIRI. For this case, with no cloud interference, little water vapor interference and a good estimate of the background reference the accuracy is estimated to be $\pm 3 \mathrm{DU}$, or twice better than that of SEVIRI.

\subsection{CALIOP}

CALIPSO, with the CALIOP lidar on board was launched on April 28, 2006 to study the impact of clouds and aerosols on the Earth's radiation budget and climate (Winker et al., 2003, 2007). As part of the A-train, CALIPSO flies at $705 \mathrm{~km}$ altitude in a $98^{\circ}$ inclination sun-synchronous polar

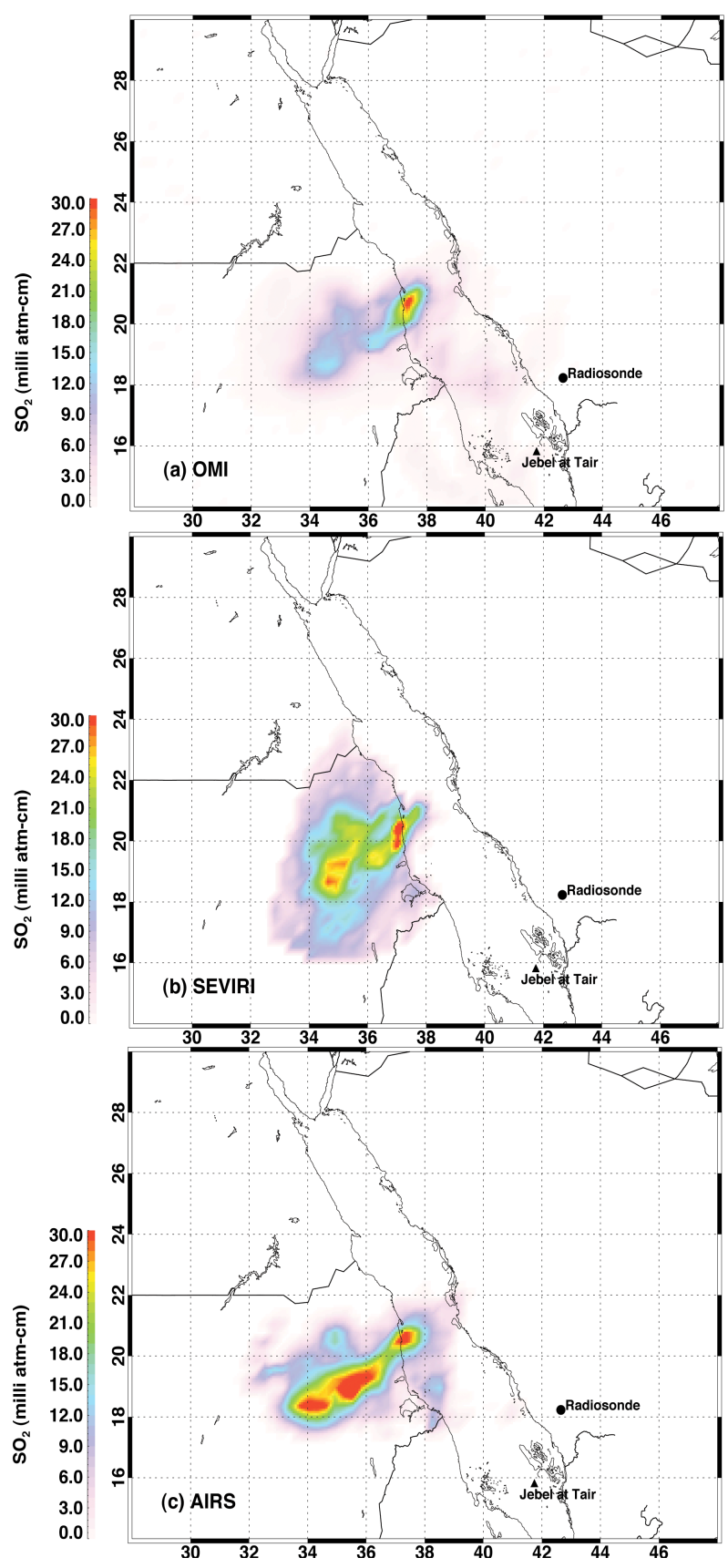

Fig. 3. Column $\mathrm{SO}_{2}$ retrievals from three satellite instruments on 1 October 2007. (a) OMI at 10:57-11:01 UT, (b) SEVIRI averaged over four consecutive times: 10:12, 10:27, 10:42 and 10:57 UT and (c) AIRS at 10:42 UT.

orbit with equator-crossinG at 10:30 UT and a 16-day repeat cycle. CALIOP provides profiles of backscatter at $532 \mathrm{~nm}$ and $1064 \mathrm{~nm}$, as well as the degree of the linear polarization of the $532 \mathrm{~nm}$ signal. An altitude-dependent on-board averaging scheme is employed, reducing the original sampling resolution of $30 \mathrm{~m}$ in the vertical and $333 \mathrm{~m}$ in the horizontal to $60 \mathrm{~m}$ vertical and $1 \mathrm{~km}$ horizontal resolution in the 


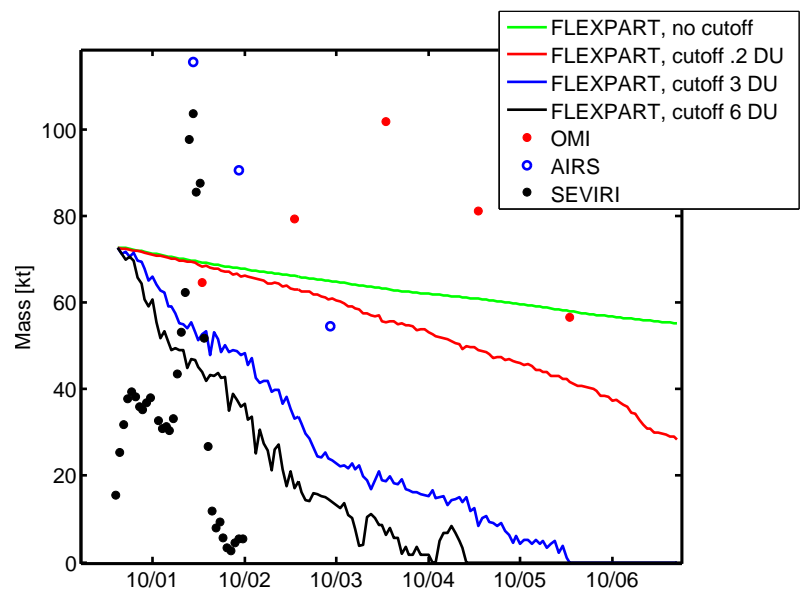

Fig. 4. Total mass of $\mathrm{SO}_{2}[\mathrm{kt}]$ as observed by SEVIRI (black dots), AIRS (blue dots) and OMI (red dots) in the volcanic plume as a function of time. The total mass was calculated using all $\mathrm{SO}_{2}$ columns above $6 \mathrm{DU}, 3 \mathrm{DU}$ and $0.2 \mathrm{DU}$ for SEVIRI, AIRS and OMI, respectively in the region around the observed volcanic plume. The mass obtained from the FLEXPART reference simulation is shown without a minimum column threshold (green line) and with the same thresholds as used for the satellite data (black, blue, and red lines, respectively).

altitude range between 8.2 and $20.2 \mathrm{~km}$ a.s.l. CALIOP's ability to detect distinct volcanic sulfate aerosol layers in the stratosphere has already been seen within the first CALIPSO image released (Carn et al., 2007a). The backscatter data from 7 June 2006 provided an accurate altitude localization of the volcanic plume from the eruption of Soufriere Hills, on Montserrat on 20 May 2006. Early validation from McGill et al. (2007) showed that the minimum detectable backscatter at $532 \mathrm{~nm}$ for sub-visible cirrus at $15 \mathrm{~km}$ altitude at resolution of $60 \mathrm{~m}$ vertical by $5 \mathrm{~km}$ horizontal during night-time is $(8 \pm 1) \times 10^{-7} \mathrm{~m}^{-1} \mathrm{sr}^{-1}$, which is in good agreement with the theoretical value of $7 \times 10^{-7} \mathrm{~m}^{-1} \mathrm{sr}^{-1}$ (Vaughan et al., 2005). They found an altitude agreement between airborne lidar data and CALIOP profiles to be within one CALIOP range bin $(60 \mathrm{~m})$.

We have used the total attenuated backscatter at $532 \mathrm{~nm}$, which is a primary level 1 data product. The attenuated backscatter profile is the calibrated, range-corrected, laser energy normalized, baseline-subtracted lidar return signal (see Hostetler et al., 2006, for more details). Due to the better signal-to-noise ratio we have used night-time transects only. The data were ordered and downloaded via ftp from the NASA Langley Atmospheric Science Data Center (ASCD, see http://eosweb.larc.nasa.gov/).

To enhance the visibility of the faint layers originating from the eruption in the CALIOP backscatter plots, we have substracted a smoothed average ( $3 \mathrm{~km}$ vertically and 2$3^{\circ}$ horizontally) from a nearby region without any visible aerosol layer from the attenuated backscatter profiles. As we intend to use the result for a qualitative comparison between CALIOP profiles and FLEXPART simulations, this approach - contrary to a full retrieval of e.g. backscatter ratios (level 2 data are expected in 2008) - seems appropriate. Furthermore, the data have been median filtered over 300 profiles (ca. $100 \mathrm{~km}$ ) horizontally and $300 \mathrm{~m}$ (5 range bins) vertically to decrease the CALIOP resolution to that of the FLEXPART output.

\subsection{Measurement comparison}

Differences in the $\mathrm{SO}_{2}$ column amount retrieved from AIRS, OMI and SEVIRI are found to be as much as $30 \%$, with, in this case the IR retrievals giving larger columns than the OMI UV retrievals. Figure 3 shows an example of retrievals from OMI, SEVIRI and AIRS at around 10:30 UT on 1 October 2007, about $23 \mathrm{~h}$ after the eruption. The patterns of $\mathrm{SO}_{2}$ distribution within the cloud are generally similar but there are noticeable differences. On average, AIRS columns are about 20\% larger than OMI columns and SEVIRI columns are about $10 \%$ larger than OMI. Generally, there is northwestward transport of the $\mathrm{SO}_{2}$ during the first day, which suggests transport with the southeasterly winds in the upper troposphere and lower stratosphere, which are found in the ECMWF data (Fig. 2). The plume covers a relatively large area, which indicates that $\mathrm{SO}_{2}$ was injected into the atmosphere at more than one altitude, thus allowing the vertical wind shear to rapidly disperse the plume.

Spatial integration of $\mathrm{SO}_{2}$ columns over the volcanic plume yields the total mass of $\mathrm{SO}_{2}$ in the atmosphere - shown in Fig. 4 as a function of time. The data suggest an emission of the order of $80 \mathrm{kt} \mathrm{SO}$ but the mass varies substantially, both between platforms and with time. For instance, AIRS shows a decrease of $\mathrm{SO}_{2}$ from 1 to 3 October (as it might be expected due to deposition and chemical conversion of $\mathrm{SO}_{2}$ ), whereas OMI shows an increase during the same time period and a decrease only after that. The model shows that only $1 \%$ of the tracer is removed by dry deposition after $3 \mathrm{~d}$, so chemical conversion plays a greater role. The reason for the initial increase observed with OMI is not clear. SEVIRI values fluctuate strongly, showing first a steep increase, which is probably related to the fact that SEVIRI cannot see the entire $\mathrm{SO}_{2}$ column when there is a lot of $\mathrm{SO}_{2}$, and then a steep decrease, which is related to the limited sensitivity of the retrieval. In the FLEXPART model calculations (for description, see section 4), the total $\mathrm{SO}_{2}$ mass decreases slowly if no cutoff is used, suggesting a lifetime of a few weeks. It drops steeply with the 6 DU threshold used for SEVIRI, demonstrating that the SEVIRI retrieval is not sensitive enough for obtaining useful information later than about $36 \mathrm{~h}$ after the eruption. The differences in the patterns and in the total mass retrieved from each of the sensors have repercussions for the inverse modeling. In order to remove at least the biases in the total mass, we normalized AIRS and hourly SEVIRI total 
masses for the first $24 \mathrm{~h}$ to the OMI total mass from the first overpass, which we assume to be most accurate.

\subsection{Height sensitivity}

The infrared retrieval schemes have a significant sensitivity to the height of the $\mathrm{SO}_{2}$ cloud. Error in the retrieval of column abundance arises from error in the assumed height of the $\mathrm{SO}_{2}$ cloud. For remote sounding within an infrared absorption band, neglecting the effects of clouds and other absorbers, the sensitivity to height can be assessed from the radiative transfer equation,

$I_{v}=\int_{1}^{0} B_{v}[T] d \tau$

where $I_{v}$ is the radiance emerging at the top of the atmosphere at wavenumber $\nu, B$ is the Planck function, and $\tau$ the transmittance. The Planck function varies with wavenumber and temperature, which varies with height. The transmittance depends on the absorber profile $(q)$ and is also a function of wavenumber and height. Changing variables,

$I_{\nu}=\int_{0}^{\infty} B_{v}[T(z)] \frac{d \tau_{v}(q, z)}{d z} d z$

the weighting function is:

$W=\frac{d \tau_{v}(q, z)}{d z}$.

Weighting functions for a monochromatic channel situated near $7.3 \mu \mathrm{m}$ are shown in Fig. 5 for the case of a US Standard Atmosphere with background $\mathrm{SO}_{2}$ and for a perturbed atmosphere with a layer of $\mathrm{SO}_{2}$ injected at $15 \mathrm{~km}$. The background atmosphere weighting function peaks near to 600 $\mathrm{hPa}$, while the weighting function for the perturbed atmosphere peaks close to the location of the $\mathrm{SO}_{2}$ injection. In practice the $7.3 \mu \mathrm{m}$ channel is sensitive to the profiles of both water vapor and $\mathrm{SO}_{2}$ and the transmittance of the atmosphere at this wavelength may be regarded as the product of the transmittances of the individual gases. The weighting function can then be written,

$W_{i, j}=\tau_{i} \frac{\partial \tau_{j}}{\partial z}+\tau_{j} \frac{\partial \tau_{i}}{\partial z}$

where the subscripts $i, j$ represent the two gases, in this case $\mathrm{H}_{2} \mathrm{O}$ and $\mathrm{SO}_{2}$. If the atmosphere contained only gas $i$ then $\tau_{j}=1, \frac{\partial \tau_{j}}{\partial z}=0$ and the weighting function is that due to gas $j$ alone. This means that whenever $\mathrm{SO}_{2}$ and water vapor are collocated it will be difficult to quantify the $\mathrm{SO}_{2}$. The AIRS retrieval uses an off-line radiative transfer model and a least squares estimation that reduces the error due to inaccurate knowledge of the absorber height.

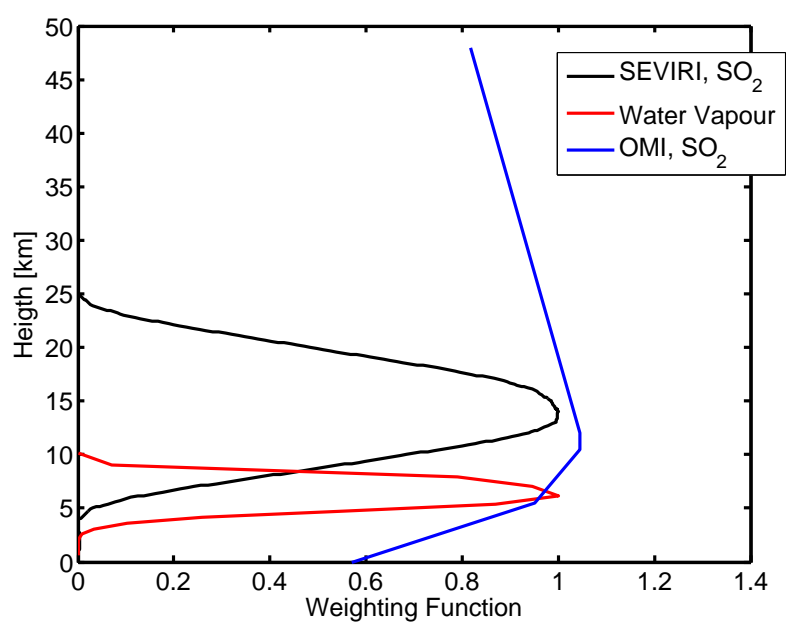

Fig. 5. Infrared weighting functions for a water vapor channel near $7.3 \mu \mathrm{m}$, and for the same channel with an atmosphere containing an $\mathrm{SO}_{2}$ layer near $15 \mathrm{~km}$. Also shown is the OMI weighting function for a clear atmosphere, adapted from Figure 7 of Yang et al. (2007).

The OMI UV retrievals also have a sensitivity to the height of $\mathrm{SO}_{2}$, as explained by Yang et al. (2007). The weighting functions in the OMI retrievals are determined for distinct Umkehr layers with layer base altitudes of (approximately) $0,5.5,10.3,14.7$ and $19.1 \mathrm{~km}$. The layer with base altitude $14.7 \mathrm{~km}$ is referred to as the $15 \mathrm{~km}$ retrieval and this is the $\mathrm{SO}_{2}$ product used in our study. Averaging kernels (weighting functions) for the OMI retrieval peak between 5 and $15 \mathrm{~km}$, are quite broad and depend on the surface characteristics as well as the profiles of $\mathrm{SO}_{2}$ and the presence of clouds (see Fig. 7 of Yang et al., 2007). For this study we have used an averaging kernel for a cloud free atmosphere with $\mathrm{SO}_{2}$ uniformly distributed in Umkehr layer 3 as illustrated in Fig. 5.

\section{Atmospheric transport modeling}

Transport of the volcanic $\mathrm{SO}_{2}$ plume was simulated with the Lagrangian particle dispersion model FLEXPART (Stohl et al., 1998, 2005, see also http://transport.nilu.no/flexpart). FLEXPART was validated with data from continental-scale tracer experiments (Stohl et al., 1998) and has been used in a large number of studies on long-range atmospheric transport (e.g., Stohl et al., 2003; Damoah et al., 2004; Eckhardt et al., 2007), also of volcanic plumes (Prata et al., 2007). For this study it was driven with operational analyses from the European Centre for Medium-Range Weather Forecasts (ECMWF, 2002) with $1^{\circ} \times 1^{\circ}$ resolution. In addition to the analyses at 00:00, 06:00, 12:00 and 18:00 UT, 3-hour forecasts at 03:00, 09:00, 15:00 and 21;00 UT were used. The ECMWF data has 91 vertical layers with a resolution of about $430 \mathrm{~m}$ near $16 \mathrm{~km}$ a.s.l. 


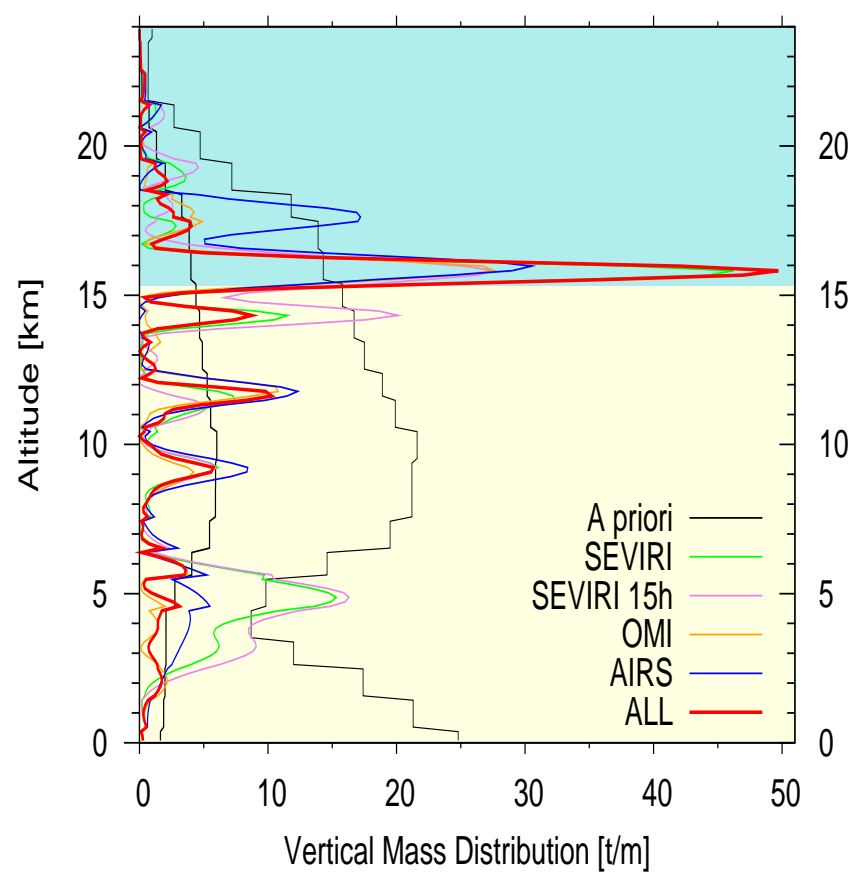

Fig. 6. Inversion results when using only SEVIRI data (green line), only OMI data (orange line), only AIRS data (blue line), and all data combined (our "reference" case, red line), during the hours 10 to 24 after the eruption. Also shown is an experiment that only used SEVIRI data from hours 10 to 15 after the eruption (violet line). The thick black line shows the a priori profile, the thin black line its assumed uncertainty.

FLEXPART calculates the trajectories of tracer particles using the mean winds interpolated from the analysis fields plus random motions representing turbulence (Stohl and Thomson, 1999). For moist convective transport, FLEXPART uses the scheme of Emanuel and Živković-Rothman (1999) as implemented by Forster et al. (2007). Calculations were done for $\mathrm{SO}_{2}$ tracer, where dry deposition and reaction with the $\mathrm{OH}$ radical were considered as sinks. The dry deposition was calculated with the resistance method (Wesely and Hicks, 1977) using data from Wesely (1989) with updates. Removal by reaction with $\mathrm{OH}$ radicals is a new feature in FLEXPART that uses monthly averaged three-dimensional $\mathrm{OH}$ concentration fields taken from a long-term simulation with the GEOS-CHEM model (Bey et al., 2001). Aqueousphase chemistry reactions were not considered. Our reference inversion (see below) was set up to use data only from the first $24 \mathrm{~h}$ after the eruption and, thus, is not critically sensitive to the removal of $\mathrm{SO}_{2}$, since the lifetime of $\mathrm{SO}_{2}$ in the upper troposphere and lower stratosphere is of the order of a few weeks. However, the removal is more important for the comparison of FLEXPART results with satellite data at later times (several days).
It was assumed that the emissions occurred in the column between the ground and $24 \mathrm{~km}$ above ground level (agl), or some subset of this column, above the volcano. The total height range was divided into 160 layers each $150 \mathrm{~m}$ deep. For every layer, a simulation with $1 \mathrm{~kg}$ of tracer, carried by 150000 particles and released uniformly within the layer along a vertical line source, was performed. The simulations extended over the four days following the eruption. Concentrations were calculated on the same $0.3^{\circ} \times 0.3^{\circ}$ output grid to which the satellite data were re-sampled, with 9 layers of $2 \mathrm{~km}$ vertical resolution between $4 \mathrm{~km}$ and above $22 \mathrm{~km}$ agl, a single layer between the surface and $4 \mathrm{~km}$ a.g.l., and another layer from $22-50 \mathrm{~km}$ a.g.l. Total atmospheric columns were calculated by weighting the concentrations in the 11 model layers with the weighting functions (averaging kernels) shown in Fig. 5 (see Sect. 3.6). These model-derived column values represent source-receptor relationships, since they were obtained with a unit mass as source. The actual mass released at each level is determined through the inversion.

Following the inversion, a single longer simulation over 14 days was made releasing 3 million particles according to the estimated emission profile. The output from this simulation was produced at higher vertical $(500 \mathrm{~m})$ but coarser horizontal $\left(1^{\circ}\right)$ resolution. It was used for comparisons with independent data.

\section{Inversion method}

The estimation of the $\mathrm{SO}_{2}$ emission profile ( $\mathrm{SO}_{2}$ sources) is based on the analytic inversion method of Seibert (2000, 2001). It has been improved by allowing an a priori for the unknown sources, a Bayesian formulation considering uncertainties for the a priori and the observations, and an iterative algorithm for removing negative emission values.

The $n=160$ unknowns (source elements) are put into a vector $\boldsymbol{x}$, while the $m$ observed values are put into a vector $\boldsymbol{y}^{\boldsymbol{o}}$, where the superscript $o$ stands for observations. Modeled values $\boldsymbol{y}$ corresponding to the observations can be calculated as

$y=M x$

where $\boldsymbol{M}$ is the $m \times n$ matrix of source-receptor relationships calculated with FLEXPART.

One may expect to obtain $\boldsymbol{x}$ by means of multiple linear regression which minimizes the sum of the squared deviations model and observation. However, with the fine resolution of the source that has been introduced, observations do probably not contain sufficient information to constrain well all elements of the source vector, making the problem ill-conditioned. Therefore, regularization or, in other words, additional information is necessary to obtain a meaningful solution. Seibert (2000) has shown that simple Tikhonov regularization, which constrains the squared length of the solu- 
tion vector $\|\boldsymbol{x}\|^{2} \equiv \boldsymbol{x}^{T} \boldsymbol{x}$ in combination with a further term requiring the solution to be smooth can yield useful solutions for inversions of atmospheric trace substances even without explicit a priori source values. Implicitly, Tikhonov regularisation means zero a priori values. Including an explicit a priori source vector $\boldsymbol{x}^{a}$, we can write

$\boldsymbol{M}\left(\boldsymbol{x}-\boldsymbol{x}^{a}\right) \approx \boldsymbol{y}^{o}-\boldsymbol{M} \boldsymbol{x}^{a}$

and as an abbreviation

$M \tilde{\boldsymbol{x}} \approx \tilde{\boldsymbol{y}}$.

The inversion is then done by minimizing a cost function $J=J_{1}+J_{2}+J_{3}$ with the three contributions

$J_{1}=\sigma_{o}^{-2}(\boldsymbol{M} \tilde{\boldsymbol{x}}-\tilde{\boldsymbol{y}})^{T}(\boldsymbol{M} \tilde{\boldsymbol{x}}-\tilde{\boldsymbol{y}})$

$J_{2}=\tilde{\boldsymbol{x}}^{T} \operatorname{diag}\left(\sigma_{\boldsymbol{x}}{ }^{-2}\right) \tilde{\boldsymbol{x}}$

$J_{3}=\epsilon(\boldsymbol{D} \tilde{\boldsymbol{x}})^{T} \boldsymbol{D} \tilde{\boldsymbol{x}}$.

$J_{1}$ measures the misfit model and observation, $J_{2}$ the deviation from the a priori values, and $J_{3}$ the deviation from smoothness. $\sigma_{o}$ is the standard error of the observations, and $\sigma_{x}$ the vector of standard errors of the a priori values. The operator $\operatorname{diag}(\boldsymbol{a})$ yields a diagonal matrix with the elements of $\boldsymbol{a}$ in the diagonal. $\boldsymbol{D}$ is a tridiagonal matrix with elements on the main diagonal equal to -2 and elements of the diagonals above and below equal to 1 (discrete representation of the second derivative), and $\epsilon$ is a regularisation parameter determining the weight of this smoothness constraint compared to the other two terms. The standard errors of the observations could be made specific for each receptor element, as done for the a priori source vector. However, here we only specify average standard errors for each of the three satellite data sets used. If the three satellite data sets are used together in one inversion, the first part of the cost function becomes

$J_{1}=\sum_{k=1}^{3} \sigma_{o k}^{-2}\left(\boldsymbol{M}_{\boldsymbol{k}} \tilde{\boldsymbol{x}}-\tilde{\boldsymbol{y}}_{k}\right)^{T}\left(\boldsymbol{M}_{\boldsymbol{k}} \tilde{\boldsymbol{x}}-\tilde{\boldsymbol{y}}_{k}\right)$,

where the index $k$ refers to the three data sets.

The above formulation implies normally distributed, uncorrelated errors, a condition that we know to be not fulfilled. Observation errors (also model errors are subsumed in this term) may be correlated with neighboring values, and deviations from the a priori sources are likely to be asymmetric, with overestimation being more likely than underestimation as zero is a natural bound. The justification for using this approach is the usual one: the problem becomes much easier to solve, detailed error statistics are unknown anyway, and experience shows that reasonable results can be obtained.

Minimization of $J$ leads to a linear system of equations (LSE) to be solved for $\tilde{\boldsymbol{x}}$ (Menke, 1984):

$\left[\sigma_{o}^{-2} M^{T} \boldsymbol{M}+\operatorname{diag}\left(\sigma_{x}{ }^{-2}\right)+\epsilon \boldsymbol{D}^{T} \boldsymbol{D}\right] \tilde{\boldsymbol{x}}=\sigma_{o}^{-2} \boldsymbol{M}^{T} \tilde{\boldsymbol{y}}$

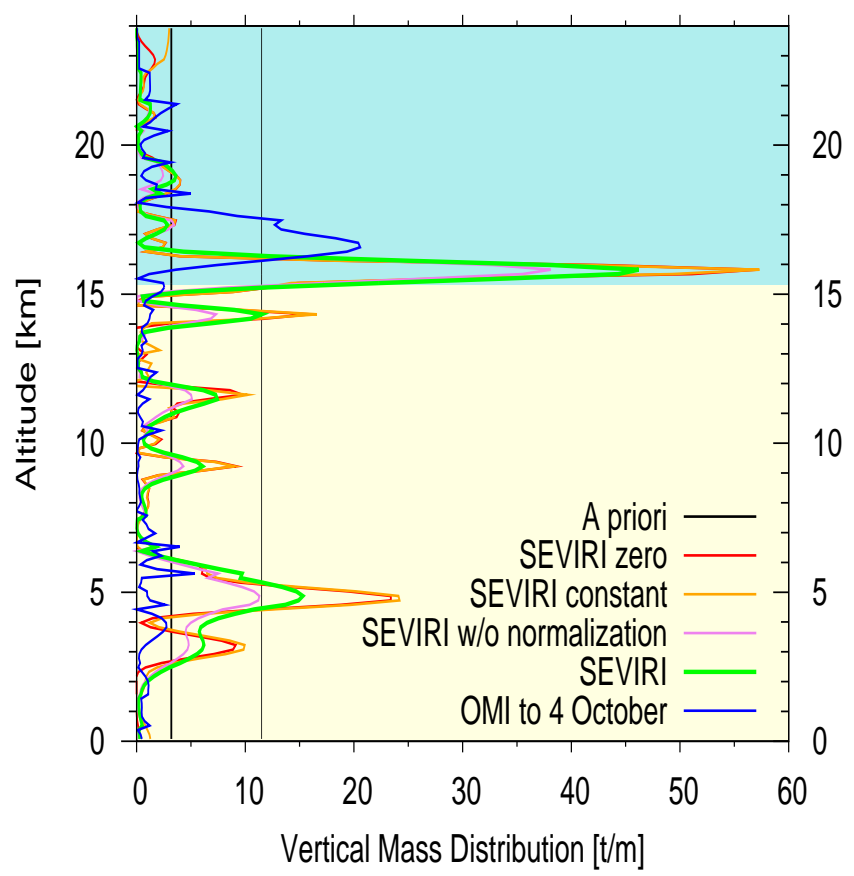

Fig. 7. Sensitivity experiments with the inversion algorithm: SEVIRI (green line) is the same result as shown in Fig. 6; SEVIRI constant (orange line) is using a flat a priori profile (shown by the thick black line) and uncertainty (thin black line); SEVIRI zero is using a zero emission a priori (red line) with the same flat uncertainty range as in the constant a priori scenario; SEVIRI w/o normalization (violet line) is using the data without normalization of the total mass to the OMI total mass, and OMI to 4 October (blue line) is using OMI data until 4 October 2007.

The LSE is solved with the LAPACK $^{3}$ driver routine SGESVX, based on LU factorisation with calibration of rows and columns (if necessary) and iterative refinement of the solution.

In the case of the inversion with all the three satellite data sets used together, we have a larger observation vector and correspondingly larger number $m^{\prime}$ of equations and a $m^{\prime} \times n$ source-receptor matrix $\boldsymbol{M}^{\prime}$ with $\boldsymbol{M}_{k}$ stacked upon each other, while the number of unknowns and the source vector remain the same. In Eq. 10, the expression $\sigma_{o}^{-2} \boldsymbol{M}^{T}$ needs to be replaced by $\boldsymbol{M}^{\prime T} \operatorname{diag}\left({\sigma_{o}^{\prime}}^{-2}\right)$, where $\sigma_{o}^{\prime}$ is a vector made up by $\left(\sigma_{o 1}, \ldots, \sigma_{o 1}, \sigma_{o 2}, \ldots, \sigma_{o 2}, \sigma_{o 3}, \ldots, \sigma_{o 3}\right), \boldsymbol{M}$ by $\boldsymbol{M}^{\prime}$, and $\tilde{\boldsymbol{y}}$ by a corresponding $\tilde{\boldsymbol{y}}^{\prime}$.

Inaccuracies in model and data will in general cause such a method to find solutions containing unphysical negative emissions. In the linear framework this cannot be prevented directly as positive definiteness is a nonlinear constraint. A possible workaround that has been adopted here is to repeat the inversion after reducing the standard error values for those source vector elements that are negative, thus binding

\footnotetext{
${ }^{3}$ LAPACK is a free linear algebra package available from http: //www.netlib.org/lapack/.
} 
the solution closer to the a priori values at these heights. This procedure is iterated until the sum of all negative emissions is less than $1 \%$ of the sum of the positive emissions. During the iteration, which converges quickly, previously negative source elements may change their sign to positive. In this case, the tightening of the value towards the a prioriis reduced. The standard errors are correspondingly recalculated as

$\sigma_{x j}^{i}= \begin{cases}0.5 \sigma_{x j}^{i-1} & \text { if } \quad x_{j}^{i-1}<0 \\ \operatorname{Min}\left(1.1 \sigma_{x j}^{i-1}, \sigma_{x j}^{1}\right) & \text { if } \quad x_{j}^{i-1} \geq 0\end{cases}$

where $x_{j}^{i-1}$ and $\sigma_{x j}^{i}$ denote the $j$-th elements of the source vector and the vector of uncertainties in the apriorisource values, respectively, for the $i$-th iteration step.

For the practical application, $\boldsymbol{x}^{\boldsymbol{a}}, \boldsymbol{\sigma}_{\boldsymbol{x}}, \sigma_{o}$ and $\epsilon$ need to be assigned proper values. Regarding the a prioriemissions, Clerbaux et al. (2007) have reported a coarse-resolution IASI $\mathrm{SO}_{2}$ profile in the vicinity of the volcano, which shows a broad upper tropospheric/lower stratospheric maximum. We have taken a similarly shaped profile and a total $\mathrm{SO}_{2}$ emission of $80 \mathrm{kt}$ as our standard a priori (Fig. 6). The uncertainties are taken as proportional (a factor of 2.5 larger) to the respective emission value, except for the lowest $5 \mathrm{~km}$ where we choose a larger uncertainty because of the limited sensitivity of the sensor to $\mathrm{SO}_{2}$ in the lower troposphere. The magnitude of the uncertainty was determined by trial and error, and was chosen to allow substantial corrections to the initial profile. We tested the sensitivity of the inversion to the a priori emission profile by replacing our standard a priori with a constant emission profile and a zero emission profile (see Fig. 7).

The standard error of the observations $\sigma_{o}$ should be specified for each receptor element and should contain not only the measurement error but rather be a standard misfit between the observations and the model results. Lacking detailed information, we only specify three standard errors: $\sigma_{o 1}=6 \mathrm{DU}$ for all SEVIRI measurements, $\sigma_{o 2}=3 \mathrm{DU}$ for all AIRS measurements, and $\sigma_{o 3}=2 \mathrm{DU}$ for the OMI measurements. The SEVIRI and AIRS standard errors are the actual measurement uncertainties, assuming that here the relatively large measurement uncertainty dominates the measurement-model misfit. In contrast, OMI provides rather accurate measurements with a standard error of only 0.5 DU. Our assumed standard error of $2 \mathrm{DU}$ is four times larger, allowing for some variable biases in the OMI retrieval and, furthermore, assuming that for the comparison with OMI the larger part of the misfit stems from the model simulations and the data re-mapping.

The weight of the smoothness condition $\epsilon$ was determined subjectively as ten times the average standard error of the a priori values. This value was chosen in order to retain robust fine-scale features of the inversion but remove some of the fine-scale variation in less well constrained parts of the profile.

\section{Results}

\subsection{Inversion results}

Real-time applications (e.g., in VAACs) require a rapid response to volcanic ash hazards. After the plume has been detected and first data from satellites are available the method presented can provide the information needed in order to calculate the actual (and future) position and extent of the plume within minutes to a few hours. Less time-critical studies could take advantage also of observations taken at later times, but errors in the satellite retrievals (relative to the decreasing $\mathrm{SO}_{2}$ values in the plume) and in the model simulation grow in time.

To minimize the impact of such errors on the inversion and to make the inversion a realistic example for a real-time context, we use only data from the first $24 \mathrm{~h}$ after the eruption for our so-called "eference" inversion (we use more data in a sensitivity experiment). During the first $24 \mathrm{~h}$, hourly data from SEVIRI (averaged over 4 observations every 15 min) as well as data from single overpasses of AIRS and OMI - both about $23 \mathrm{~h}$ after the eruption (Fig. 3) - are available. All data are total column values. We did not use SEVIRI data from the first nine hours after the eruption, since SEVIRI has problems seeing the entire $\mathrm{SO}_{2}$ column when there is much $\mathrm{SO}_{2}$ present; contamination of the retrieval by eruption-induced clouds and particles is also most problematic during the first few hours.

As described in Sect. 2, the period of active vertical development of the plume is framed by the eruption time, about 11:30 UT, and the time the coldest cloud top temperature was observed, about 13:00 UT. Since the active plume development is not simulated by FLEXPART, it is not clear which starting time within this period is most appropriate for the model. We tested three intervals: 11:30-12:00 UT, 12:0012:30 UT, and 12:30-13:00 UT, during which particles were released at a constant rate. The inverted vertical emission profile was rather similar for these three intervals but the cost function was minimal and correlation between the model and the measurements was greatest for the last interval, so we consider 12:30-13:00 UT as the optimum release time.

Figure 6 shows the results from our reference inversion that used data from SEVIRI, AIRS and OMI, as well as results from inversions that used the data from only one instrument at a time, from $10-24 \mathrm{~h}$ after the eruption. The reference profile (red line in Fig. 6) shows a strong and highly localized emission peak at about $16 \mathrm{~km}$, and secondary peaks at 14 , just below $12 \mathrm{~km}$ and at $5 \mathrm{~km}$. Smaller emissions are found up to almost $20 \mathrm{~km}$, resulting in $60 \%$ of the total mass being emitted above the local tropopause at $15.3 \mathrm{~km}$ $(10 \%$ above the cold point at $16.9 \mathrm{~km})$ as determined from the ECMWF data. The sharp decrease of emissions around the cold point could be recovered well by the method because of the strong change in the winds at this altitude (Fig. 2). It is in excellent agreement with the minimum observed cloud 
top temperature (see Sect. 2), which also indicates a plume top at 16.5 or $17.1 \mathrm{~km}$ a.s.l. The emission maxima are collocated with layers of enhanced stability in the atmospheric temperature profile (see Fig. 2), which is in agreement with the expectation that detrainment of air from the convective updraft was responsible for the injection of $\mathrm{SO}_{2}$ into the ambient flow.

The estimated emission profile is remarkably robust. Inversions done separately for all three platforms (SEVIRI green line, OMI orange line, AIRS blue line in Fig. 6) yield results that are generally very similar to our reference result. The largest difference occurs for the inversion using AIRS data, which broadens the $16-\mathrm{km}$ peak obtained with the other data sets and shifts it upward by $1-2 \mathrm{~km}$. Large differences occur also below $6 \mathrm{~km}$, where the SEVIRI results show a broad and strong peak which is much weaker in the AIRS and OMI results. These large differences in the lower troposphere result from the decreasing sensitivity of the $\mathrm{SO}_{2}$ retrievals with decreasing altitude and, thus, a relatively poor constraint on emissions there. Overall, however, Fig. 6 demonstrates that data from a single platform would have sufficed to obtain an emission profile very similar to our reference profile. The results using the SEVIRI data only are particularly encouraging, since SEVIRI data are available every 15 min and can most easily be used in real time. Encouraged by this, we made another inversion using SEVIRI data only from 10 to $15 \mathrm{~h}$ after the eruption (violet line in Fig. 6). Even this profile is reasonably close to our reference profile such that a relatively quick estimate of the emission profile could have been made in a real-time situation.

In Fig. 7, the result of an inversion using only OMI data until 4 October is shown (blue line). This results in a generally similar profile but a reduced peak at $16 \mathrm{~km}$ and increased emissions at $17-18 \mathrm{~km}$, which is somewhat similar to the result using the AIRS data from the first $24 \mathrm{~h}$ (blue line in Fig. 6). This inversion yields a much better agreement with OMI data up to 10 days after the eruption but it is possible that the higher altitude of the emission peak is an artifact of the inversion which compensates for growing errors in the transport simulation. For instance, there might have been lofting of the plume en route, which was not properly simulated by FLEXPART. This could have been assisted by radiative heating caused by $\mathrm{SO}_{2}$ and ash. However, given that we found no evidence of significant amounts of ash, the heating by $\mathrm{SO}_{2}$ alone would probably have been less than $2 \mathrm{~K} / \mathrm{d}$ (see Fig. 4 of Gerstell et al., 1995), even on the first day when $\mathrm{SO}_{2}$ columns where largest.

All the a posteriori emission profiles deviate strongly from our a priori estimate. To further explore the sensitivity to the a priori profile, we show results of inversions using SEVIRI data with vertically constant (orange line) and zero a priori (red line) emissions. For the constant a priori profile, the total mass is the same as used previously (green line in Fig. 7, repeated from Fig. 6 for convenience). At most altitudes, the results are quite similar and, thus, not very sensitive to changes in the a priori profile. Relatively large changes occur below about $5 \mathrm{~km}$ and above $23 \mathrm{~km}$ where the results are less well constrained by the measurements and, thus, are bound tighter towards the a priori than at other altitudes.

We also explored the sensitivity of our results to the normalization of the total mass to the OMI total mass. Removing this normalization leads to strong fluctuations of the total mass observed by SEVIRI from hour to hour (see Fig. 4), which in turn produce weaker correlations between observed and simulated $\mathrm{SO}_{2}$. Nevertheless, the resulting emission profile (violet line in Fig. 7) is still similar to the normalized case (green line), although the total emitted mass is somewhat reduced.

\subsection{Comparison with independent OMI data}

Next we compare the results of a FLEXPART simulation using the reference emission profile as input with independent OMI data from the period 1 to 6 October. The daily $\mathrm{SO}_{2}$ maps shown in Fig. 8 are composites of data from several overpasses occurring over a period of a few hours. The FLEXPART results have been sampled in the same way, i.e., at the hours of the OMI overpasses and using the OMI weighting function. On 1 October (Fig. 8a), roughly $23 \mathrm{~h}$ after the eruption, the $\mathrm{SO}_{2}$ cloud already covers a relatively large area to the northwest of Jebel at Tair (see also Fig. 3). There is excellent agreement between OMI and FLEXPART, which is perhaps not surprising because these OMI data were part of the input used in the inversion. Nevertheless, the good agreement shows that the ECMWF winds are compatible with the actual dispersion of the volcanic plume and that FLEXPART can handle the transport situation very well. The western part of the simulated plume is the highest (up to $20 \mathrm{~km}$ altitude), whereas the eastern part contains contributions mainly from $10-16 \mathrm{~km}$, with smaller contributions also from lower altitudes.

Over the next $24 \mathrm{~h}$, the plume changes travel direction and heads eastward. On 2 October (Fig. 8b), both OMI and FLEXPART show a filamentary two-tailed plume stretching over more than $25^{\circ}$ longitude. On 3 October (Fig. 8c), the plume already stretches over more than $40^{\circ}$ longitude. This filamentation is due to vertical wind shear, with the eastern part of the plume being located at about $15-16 \mathrm{~km}$ a.s.l. and the western part being located at about $17-18 \mathrm{~km}$ a.s.l. FLEXPART still reproduces the overall plume shape well, including the plume's two long tails. However, it appears that FLEXPART has too much $\mathrm{SO}_{2}$ in the plume's head near $75^{\circ} \mathrm{E}$ (at altitudes of about $15-16 \mathrm{~km}$ ) and too little in the northern tail of the plume - in particular, the OMI maximum near $33^{\circ} \mathrm{E}$ is not reproduced. The alternative inversion result which used OMI data until 4 October reproduces the $\mathrm{SO}_{2}$ distribution much better as it has lower emissions at $15-16 \mathrm{~km}$ and higher emissions at $17-18 \mathrm{~km}$ (not shown). 

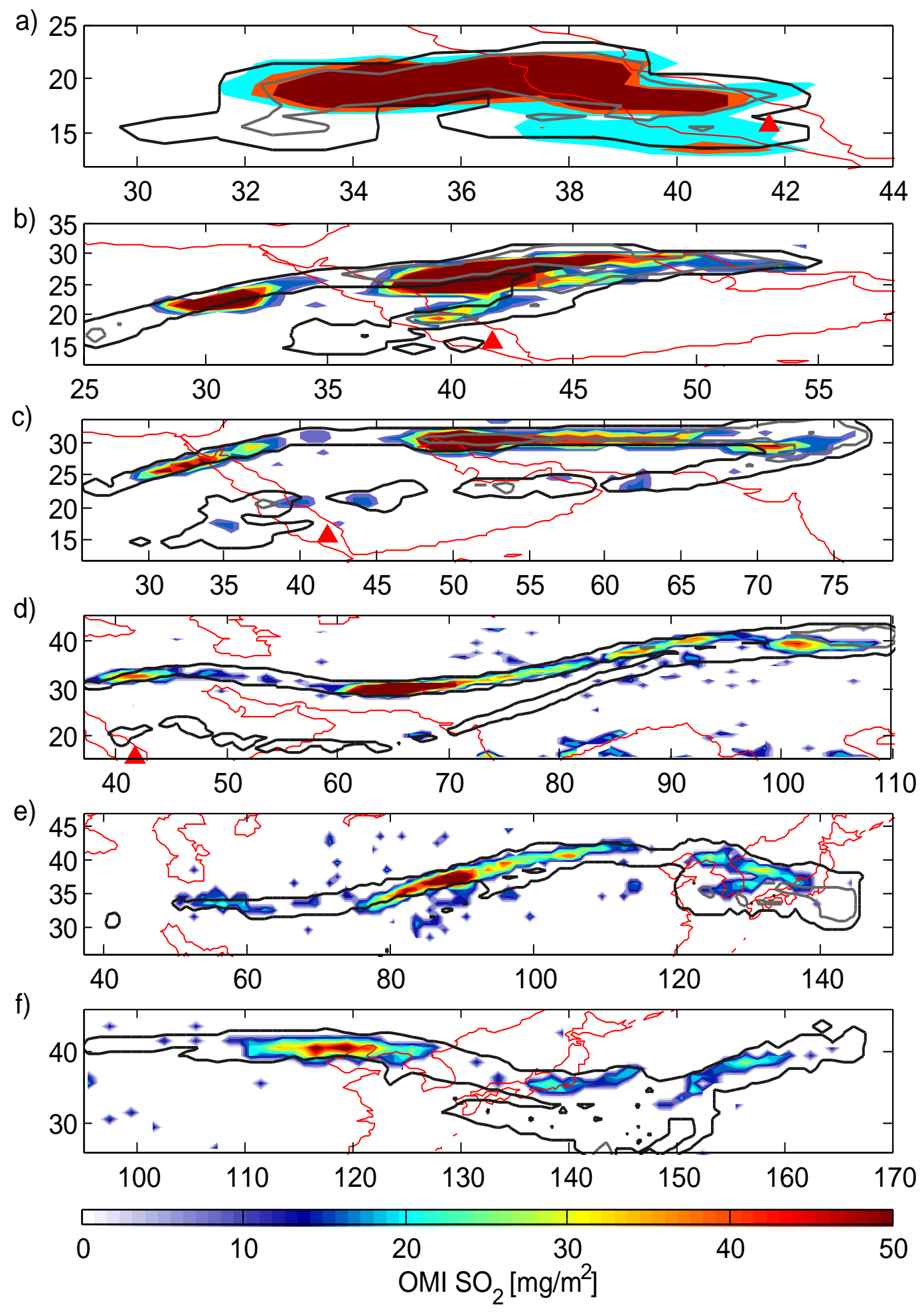

Fig. 8. Comparison of $\mathrm{SO}_{2}$ columns measured by OMI and simulated by FLEXPART using the emission profile from our reference inversion for (a) 1 October 09:00-12:00 UT, (b) 2 October 09:00-12:00 UT, (c) 3 October 07:00-13:00 UT, (d) 4 October 04:00-12:00 UT, (e) 5 October 04:00-11:00 UT, (f) 6 October 02:00-07:00 UT. The satellite data are shown by the color shading and the FLEXPART results are shown as isolines for $1 \mathrm{mg} \mathrm{m}^{-2}$ (thick black line) and $30 \mathrm{mg} \mathrm{m}^{-2}$ (thick grey line). Continental outlines are shown by thin red lines. Notice that the individual panels show different regions - axes are labeled with longitudes and latitudes, respectively. The location of the volcano is marked with a red triangle in the first four panels. 
On 4 October (Fig. 8d), both the observed and simulated plume stretch over more than $70^{\circ}$ longitude. The leading part of the plume has almost reached the eastern seaboard of Asia. The southern tail, located near $10-12 \mathrm{~km}$, starts disappearing in the model and has already nearly disappeared in the observations. On 5 October, the plume's head has reached Japan, and the southern tail has now disappeared in both the model and the measurements. The model strongly overestimates $\mathrm{SO}_{2}$ in the plume head which may be partly due to a insufficiently rapid removal of $\mathrm{SO}_{2}$ in the model in this tropospheric part of the plume - notice that aqueous-phase chemistry was ignored in the model calculations but might have been important in this part of the plume. ECMWF data indicate the occurrence of cloud features in this region. On 6 October (Fig. 8f), the satellite measurements become scattered, whereas the model still suggests a continuous plume. By this time, the satellite retrievals might have difficulties seeing the full plume, as $\mathrm{SO}_{2}$ columns in parts of the plume have become quite low and clouds obscure part of the plume. Nevertheless, it seems the model overestimates $\mathrm{SO}_{2}$ columns south of $35^{\circ} \mathrm{N}$ - again, this part of the plume is in the troposphere and conversion to sulfate may have been quicker in reality than in the model. This is supported by CALIPSO observations on 7 October (see later), which show an aerosol cloud at $14 \mathrm{~km}$ a.s.l. in a region where OMI sees little $\mathrm{SO}_{2}$.

Overall, the agreement between the model-simulated and the observed plume transport is quite good, even though not all plume maxima are well captured. The outstanding discrepancy is that the trailing part of the plume - which originated in the model from near $17-18 \mathrm{~km}$ - is underestimated, whereas the leading part - which originated in the model from near $15-16 \mathrm{~km}$ - is overestimated. Indeed, the alternative inversion using OMI data until 4 October redistributes the emissions to higher altitudes compared to our reference inversion (Fig. 7). Whether this really indicates an initially higher emission, a self-lofting of the plume to greater altitudes en route, or other errors in the model transport is not clear.

\subsection{Comparison with CALIPSO}

Aerosols formed by the conversion of $\mathrm{SO}_{2}$ to sulfate cause enhanced backscatter. In the following, we compare CALIPSO profiles of total attenuated backscatter at $532 \mathrm{~nm}$ with $\mathrm{SO}_{2}$ concentrations simulated by FLEXPART. The comparison is qualitative as we compare two very different quantities. FLEXPART does account for the oxidation of $\mathrm{SO}_{2}$ by $\mathrm{OH}$ radicals but has no tracer for the oxidation product, sulfate, which causes the backscatter. Sulfate can be removed by precipitation in the troposphere such that tropospheric features found in the FLEXPART results may not always be seen by CALIPSO. Nevertheless, a qualitative comparison of plume features is sufficient for our purpose of evaluating the altitude of the simulated plume.
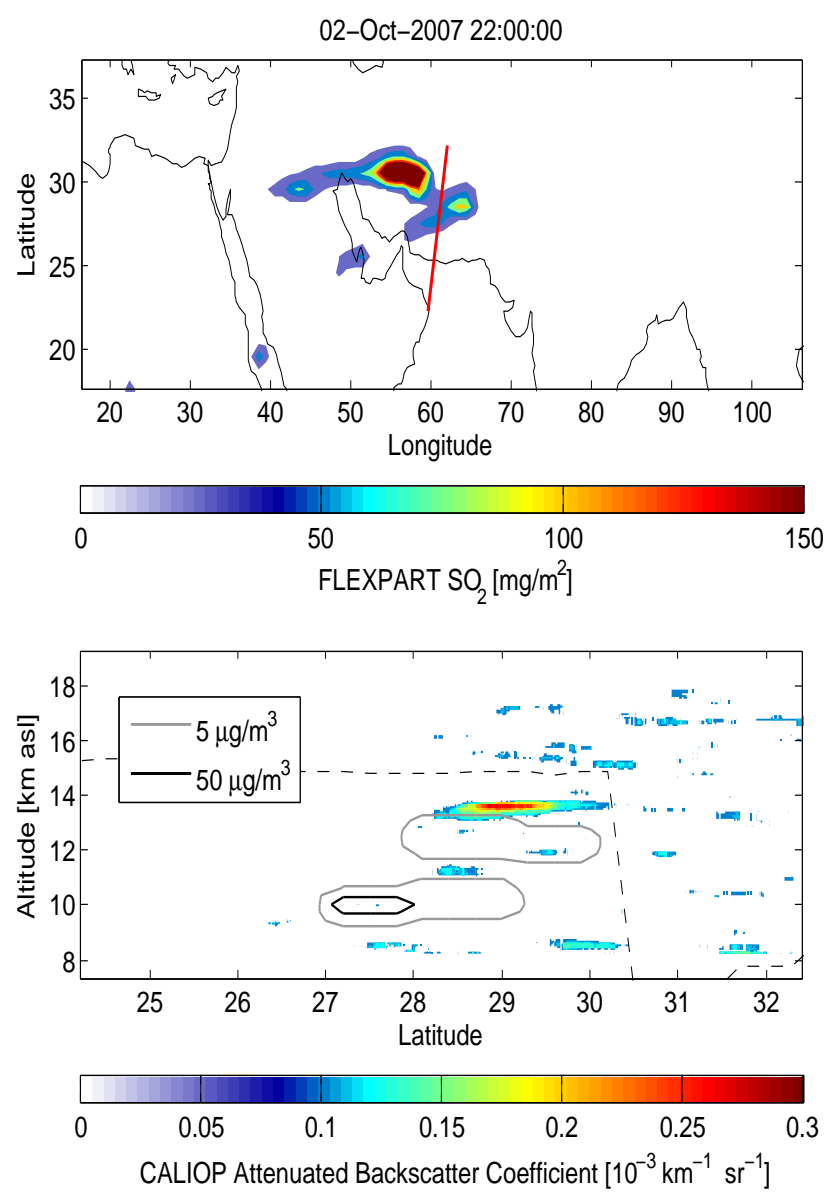

Fig. 9. Comparison of CALIPSO attenuated backscatter with $\mathrm{SO}_{2}$ concentrations simulated by FLEXPART on 2 October at 22:00 UT. The map (upper panel) shows total columns of $\mathrm{SO}_{2} \mathrm{sim}$ ulated by FLEXPART. The red line indicates the location of the CALIPSO nadir track. In the lower panel, the CALIPSO data are shown by the color shading and the FLEXPART results are plotted as isolines for $50 \mu \mathrm{g} \mathrm{m}^{-3}$ (thick black line) and $5 \mu \mathrm{g} \mathrm{m}^{-3}$ (thick grey line). The tropopause altitude calculated from the ECMWF analyses is plotted as a thin dashed black line.

Enhanced backscatter can also be caused by clouds. At the altitudes where we find the volcanic plume (about 14$18 \mathrm{~km}$ ), there may be ice clouds (cirrus) which can be clearly identified in the CALIPSO data by their depolarization signal and "normally" much higher backscatter. The suspected volcanic plume features are so faint that even though the scattering layers can be identified unambiguously, a beyond-doubt identification of these layers as sulfate aerosol is difficult. However, we can rule out alternative aerosol sources, since the CALIPSO backscatter features are found only in the region where the volcanic plume was observed by the other satellite instruments. In addition, the altitudes of $14-18 \mathrm{~km}$ are very seldomly reached by normal convection in the subtropics or middle latitudes, suggesting a violent injection of the aerosol into this height range. We did not attempt to identify aerosol backscatter features at lower altitudes where 

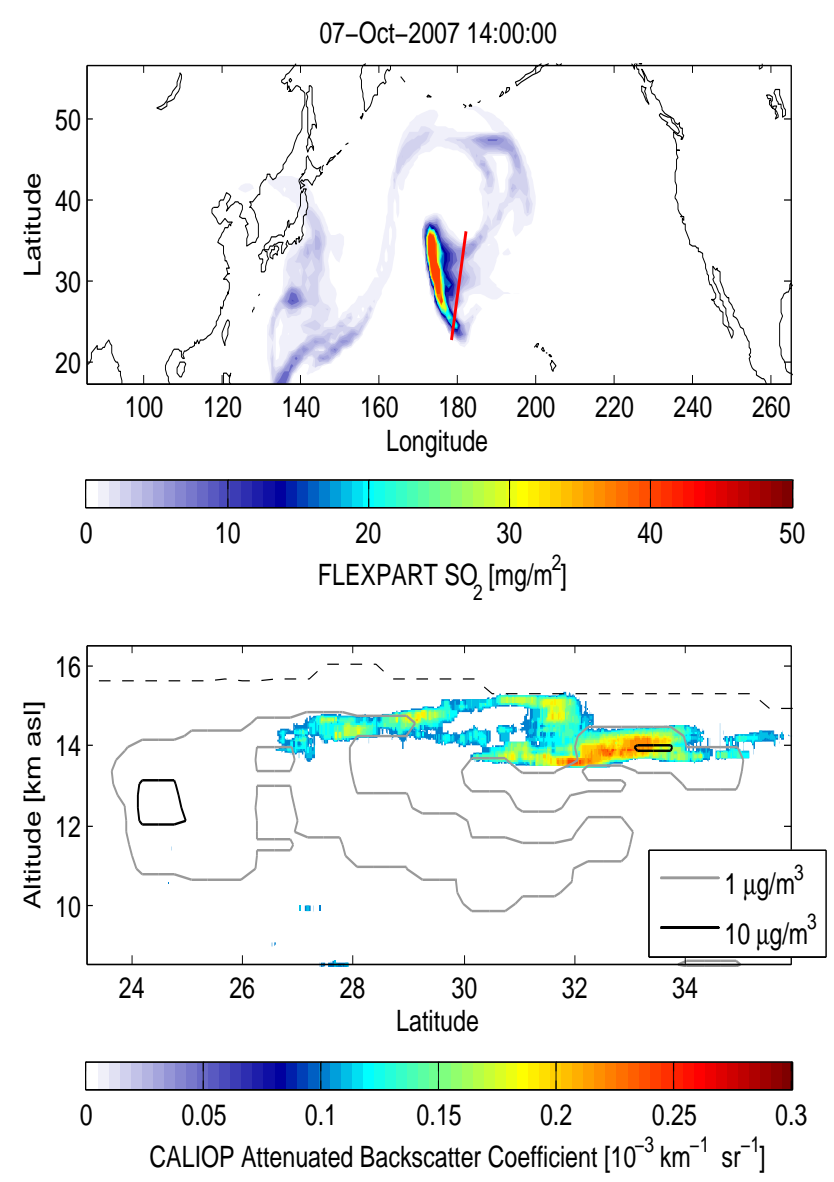

Fig. 10. Same as Fig. 9 but for 7 October at 14:00 UT.

washout may have removed the aerosol and where it would be difficult to ascertain the volcanic origin of the aerosol. Because of the slow conversion of $\mathrm{SO}_{2}$ into sulfate, some of the best CALIPSO observations of the volcanic plume were made after more than one week, even though the dilution of the plume counteracts sulfate formation.

CALIPSO starts observing the volcanic plume on 2 October ( $58 \mathrm{~h}$ after the eruption) (Fig. 9). The lidar profile cuts through the plume's head and observes a thin veil of enhanced backscatter between $28-30^{\circ} \mathrm{N}$ at about $13-14 \mathrm{~km}$, approximately $2 \mathrm{~km}$ below the tropopause. The plume simulated by FLEXPART stretches further south and is tilted, reaching down to $10 \mathrm{~km}$ near $27^{\circ} \mathrm{N}$. The thickness of the aerosol layer is overestimated by FLEXPART, in qualitative agreement with the overestimation of $\mathrm{SO}_{2}$ in the plume's head compared to OMI observations in that part of the plume. Still, the approximate plume position is reasonably well captured.

We show two other examples where CALIPSO observed two different parts of the plume over the Pacific Ocean on 7 (Fig. 10) and 8 October (Fig. 11) On 7 October (Fig. 10), CALIPSO cut through the leading part of the plume and de-
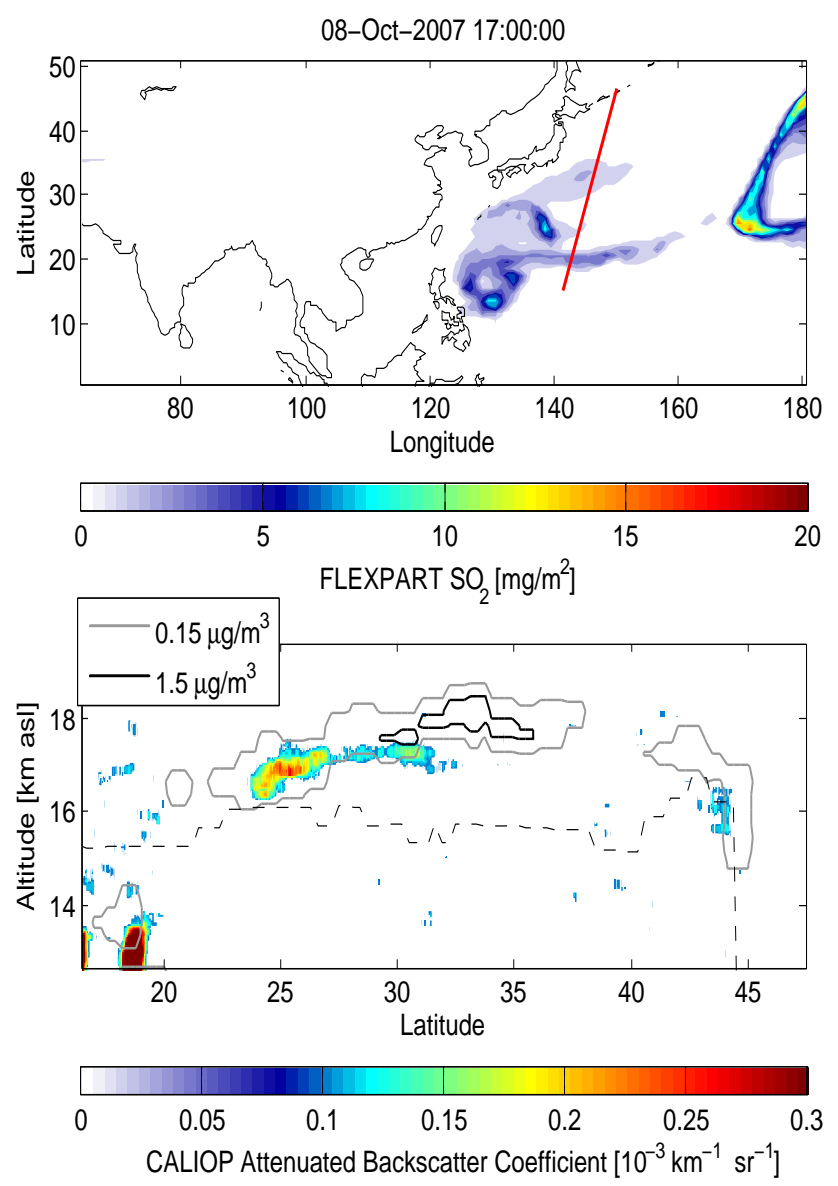

Fig. 11. Same as Fig. 9 but for 8 October at 17:00 UT.

tected a $1-2 \mathrm{~km}$ thick aerosol layer at latitudes of $27-35^{\circ} \mathrm{N}$ and at about $14-15 \mathrm{~km}$ a.s.l., just below the tropopause. The observed aerosol layer is again located at the top of the simulated plume, which is also thicker (extending down to $11 \mathrm{~km}$ ) and stretches further south (to $24^{\circ} \mathrm{N}$ ). This is one of the strongest backscatter enhancements seen by CALIPSO in the volcanic plume. Noteworthy is the fact that the OMI retrieval shows very little $\mathrm{SO}_{2}$ in this part of the plume (Fig. $8 \mathrm{f}$ shows OMI data from one day earlier), probably suggesting that a substantial fraction of the $\mathrm{SO}_{2}$ was already converted to sulfate at these altitudes.

On 8 October (Fig. 11), CALIPSO cut through the trailing part of the plume and found a thin veil of volcanic aerosol near $17 \mathrm{~km}, 1-2 \mathrm{~km}$ above the tropopause, and at latitudes of $24-32^{\circ} \mathrm{N}$. The altitude and the thickness of the simulated plume is in good agreement with the observations but it stretches over a larger latitude range. There is some evidence, both in the model results and in the observations, for a separate plume maximum near $44^{\circ} \mathrm{N}$ and $16 \mathrm{~km}$ altitude. The patches of strong backscatter in the CALIPSO data south of $20^{\circ} \mathrm{N}$ are strongly depolarized and, thus, are ice clouds. 


\section{Conclusions}

We have developed an inverse modeling technique for estimating the vertical profile of $\mathrm{SO}_{2}$ emissions from a volcanic eruption, using total column measurements of $\mathrm{SO}_{2}$ from satellites and a Lagrangian particle dispersion model. The method was applied in a case study of the explosive eruption of Jebel at Tair in the Red Sea on 30 September 2007. The good coverage of the Jebel at Tair event by satellite observations under excellent, almost cloud-free conditions and the subsequent long-range transport made it an ideal test case. Important conclusions from our work are as follows:

- From total column measurements of $\mathrm{SO}_{2}$ by a suite of satellite instruments (AIRS, OMI, SEVIRI), we estimate a total emission of $80( \pm 20) \mathrm{kt}$ of $\mathrm{SO}_{2}$ into the atmosphere. The dispersion of the $\mathrm{SO}_{2}$ plume could be observed by one of these instruments for more than a week. Starting from two days after the eruption, highly resolved vertical profiles of aerosol backscatter (sulfate aerosols are produced from the gaseous $\mathrm{SO}_{2}$ ) were available from CALIPSO.

- Our reference inversion used total-column data from AIRS, OMI and SEVIRI from the first 24 hours after the eruption and yielded an emission maximum at about $16 \mathrm{~km}$ a.s.1., and secondary maxima near 5, 9, 12 and $14 \mathrm{~km}$. According to this inversion, $60 \%$ of the mass of $\mathrm{SO}_{2}$ was injected above the tropopause located at $15.3 \mathrm{~km}$, and $10 \%$ above the cold point in the temperature profile located at $16.9 \mathrm{~km}$. The sharp decrease of emissions around the cold point agrees well with the cloud top height of 16.5 or $17.1 \mathrm{~km}$ indicated by the $12 \mu \mathrm{m}$ cloud top brightness temperature observed by SEVIRI.

- Sensitivity experiments showed that data from a single platform (either AIRS, OMI or SEVIRI alone) and from the first $24 \mathrm{~h}$ after the eruption would have sufficed to produce an emission profile in good agreement with our reference profile. Even using SEVIRI data only from the hours 10-15 after the eruption gave comparable results. This is particularly important since SEVIRI data are operationally available in real time every $15 \mathrm{~min}$. Sensitivity experiments have also shown that the results are robust against changes in the a priori emission distribution that was used in the inversion, including an a priori zero emission profile.

- Using the emission profile from the reference inversion, the overall plume dispersion as observed by OMI, including transport first to the northwest, than to the east, creation of a two-tailed elongated plume stretching over several dozen degrees of longitude, and transport across Asia and over the Pacific Ocean, could all be simulated well over the course of about a week. However, quantitatively, the relative $\mathrm{SO}_{2}$ distribution within the plume was not so well simulated. On different days, CALIPSO observations showed thin veils of aerosol in the upper troposphere/lower stratosphere region that were well collocated with the FLEXPART plume. The observed plume tended to be thinner than the simulated one. An inversion experiment using OMI data until $4 \mathrm{~d}$ after the eruption shifted the emission maximum from $16 \mathrm{~km}$ to $17-18 \mathrm{~km}$ and brought the simulation in closer agreement with both the OMI and the CALIPSO observations. However, this may not actually be due to an emission at higher altitude but may instead compensate for errors in the simulated transport (probably due to radiative heating and self-lofting of the plume) en route.

- Using our method, the emission altitudes of volcanic eruptions that reach the middle to upper troposphere and higher, can be estimated with great accuracy, thus facilitating the understanding of the climatic impacts of stratospheric $\mathrm{SO}_{2}$ injections by volcanic eruptions. An improved such understanding is needed, since injection of sulfur into the stratosphere by geo-engineering techniques has been suggested (see, e.g., Crutzen, 2006) as a way to compensate for increasing greenhouse gas concentrations - a possibly dangerous interference with the Earth system.

- Our analytical inversion method is computationally very efficient. Once the underlying dispersion model calculations are completed, the inversion only takes a few seconds on a normal personal computer. This makes it suitable also for real-time applications in Volcanic Ash Advisory Centers (VAACs).

- Aviation requires information of the volcanic threat at designated flight levels. Our results here offer a great improvement over current practice which advises the closing of the entire airspace from ground level to the uppermost flight level. Knowing that most of the ash or $\mathrm{SO}_{2}$ is above a flight level provides an opportunity for aircraft to safely fly below the hazard.

Further improvements of our inversion method could include some of the following:

- For operational application in VAACs, the procedure could be reimplemented with volcanic ash aerosol mass instead of $\mathrm{SO}_{2}$ if appropriate observations (e.g., of aerosol optical depth) are available. Alternatively, even when using the emission profile obtained from the inversion for $\mathrm{SO}_{2}$, a model simulation including the gravitational settling of aerosol could be done subsequently by assuming that the emission profiles for $\mathrm{SO}_{2}$ and ash are the same except for a vertically constant conversion factor.

- Since the eruption time (or the time when the emissions were effectively injected into the atmosphere) is 
often not known accurately, a straightforward extension of our inversion procedure would be to consider several emission intervals. The inversion algorithm could then optimize both the vertical and temporal emission distribution at the same time.

- Considerable improvement of the satellite retrievals could be expected when the actual vertical $\mathrm{SO}_{2}$ distributions from FLEXPART are used instead of standard profiles. Since the inversion uses the satellite data, an iterative scheme alternating between the satellite retrieval algorithm and the inversion algorithm would be needed. Even larger improvements would be possible by assimilating not the retrieved $\mathrm{SO}_{2}$ columns but satellite radiances. This would require the addition of a radiative transfer scheme to the dispersion model, however.

- VAACs need to track and forecast volcanic ash clouds for several days. Even with a perfect source term, atmospheric transport model output will be subject to growing errors because of errors in the underlying wind fields, interpolation errors, self-heating of the plume, etc. On the other hand, new satellite information becomes available every day or, with SEVIRI, even every $15 \mathrm{~min}$. This calls for a data assimilation procedure where the horizontal position of the ash cloud and its vertical mass profile in each grid column is regularly reassessed on the basis of a priori data from the previous model run and the new satellite information.

Acknowledgements. We thank the two anonymous reviewers for their helpful comments. We thank I. Bey for supplying us with $\mathrm{OH}$ fields from GEOS-CHEM. CALIOP data were obtained from the NASA Langley Research Center Atmospheric Science Data Center. Support of this work through various grants of the Norwegian Research Council is gratefully acknowledged. P. Seibert acknowledges funding from the Fonds zur Förderung der wissenschaftlichen Forschung (FWF grant 17924) and the Accent Network of Excellence.

Edited by: R. von Glasow

\section{References}

Bey, I., Jacob, D. J., Yantosca, R. M., Logan, J. A., Field, B. D., et al.: Global modeling of tropospheric chemistry with assimilated meteorology: Model description and evaluation, J. Geophys. Res., 106, 23073-23096, doi:10.1029/2001JD000807, 2001.

BGVN: Bulletin of the Global Volcanism Network, 32 (10), October, 2007, Dept. of Mineral Sciences, Smithsonian Institution. (Available at http://www.volcano.si.edu/gvp/reports/ bulletin/), 2007.

Carey, S., and Bursik, M.: Volcanic Plumes, In Encyclopedia of Volcanoes, Academic Press, San Diego, 527-544, 2000.

Carn, S. A., Krotkov, N. A., Yang, K., Hoff, R. M., Prata, A. J., Krueger, A. J., Loughlin, S. C., and Levelt, P. F.: Extended observations of volcanic $\mathrm{SO}_{2}$ and sulfate aerosol in the stratosphere, Atmos. Chem. Phys. Disc., 7, 2857-2871, 2007.
Carn, S. A., Krueger, A. J., Krotkov, N. A., Yang, K., and Levelt, P. F.: Sulfur dioxide emissions from Peruvian copper smelters detected by the Ozone Monitoring Instrument, Geophys. Res. Lett., 34, L09801, doi:10.1029/2006GL029020, 2007.

Chahine, M. T., Pagano, T. S., Aumann, H. H., Atlas, R., Barnet, C., et al. (2006): AIRS: Improving weather forecasting and providing new data on greenhouse gases, Bull. Am. Meteorol. Soc., 87, 911-926, doi:10.1175/BAMS-87-7-911, 2006.

Clerbaux, C., Turquety, S., Hadji-Lazaro, J., George, M., Boynard, A, Pommier, M, Coheur, P.-F., Hurtmans, D., Wespes, C., Razavi, A., and Herbin, H.: Monitoring of volcanic $\mathrm{SO}_{2}$ using thermal infrared IASI/METOP sounders (TES, IASI), paper presented at the Support to Aviation Control Service meeting, Toulouse, 26-27 November 2007.

Crutzen, P.: Albedo enhancement by stratospheric sulphur injections: A contribution to resolve a policy dilemma?, Clim. Change, 77(3-4), 211-220, doi:10.1007/s10584-006-9101-y, 2006.

Damoah, R., Spichtinger, N., Forster, C., James, P., Mattis, I., Wandinger, U., Beirle, S., and Stohl, A.: Around the world in 17 days - hemispheric-scale transport of forest fire smoke from Russia in May 2003, Atmos. Chem. Phys., 4, 1311-1321, 2004, http://www.atmos-chem-phys.net/4/1311/2004/.

ECMWF (edited by: White, P. W.): IFS Documentation, ECMWF, Reading, UK, 2002, available online at http://www.ecmwf.int

Eckhardt, S., Breivik, K., Manø, S. and Stohl, A.: Record high peaks in PCB concentrations in the Arctic atmosphere due to long-range transport of biomass burning emissions, Atmos. Chem. Phys., 7, 4527-4536, 2007, http://www.atmos-chem-phys.net/7/4527/2007/.

Emanuel, K. A. and Živković-Rothman, M.: Development and evaluation of a convection scheme for use in climate models, J. Atmos. Sci., 56, 1766-1782, 1999.

Forster, C., Stohl, A., and Seibert, P.: Parameterization of convective transport in a Lagran-gian particle dispersion model and its evaluation, J. Appl. Met. Clim., 46, 403-422, 2007.

Gerstell, M. F., Crisp, J., and Crisp, D.: Radiative forcing of the stratosphere by $\mathrm{SO}_{2}$ gas, silicate ash, and $\mathrm{H}_{2} \mathrm{SO}_{4}$ aerosols shortly after the 1982 eruptions of El Chichon, J. Climate, 8, 1060-1070, 1995.

Graf, H.-F., Li, Q., and Giorgetta, M. A: Volcanic effects on climate: revisiting the mechanisms, Atmos. Chem. Phys., 7, 4503-4511, 2007 , http://www.atmos-chem-phys.net/7/4503/2007/.

Halmer, M. M., and Schmincke, H.-U.: The impact of moderatescale explosive eruptions on stratospheric gas injections, Bull. Volcanol., 65, 433-440, 2003.

Heffter, J. L.: Volcanic ash model verification using a Klyuchevskoi eruption, Geophys. Res. Lett., 23, 1489-1492, 1996.

Hostetler, C. A., Liu, Z., Reagan, J., Vaughan, M., Osborn, M., Hunt, W. H., Powell, K. A., and Trepte, C.: CALIOP Algorithm Theoretical Basis Document, Calibration and Level 1 Data Products, PC-SCI-201, NASA Langley Res. Cent., Hampton, Va., (Available at http://www-calipso.larc.nasa.gov/resources/ project_documentation.php), 2006.

Krotkov, N. A., Carn, S. A., Krueger, A. J., Bhartia, P. K., and Yang, K.: Band Residual Difference algorithm for retrieval of SO2 from the Aura Ozone Monitoring Instrument (OMI), IEEE Trans. Geosci. Remote Sensing, AURA Special Issue, 44, 1259- 
1266, doi:10,1109/TGRS.2005.861932, 2006.

Mankin, W. G., Coffey, M. T., and Goldman, A.: Airborne observations of $\mathrm{SO}_{2}, \mathrm{HCl}$, and $\mathrm{O}_{3}$, in the stratospheric plume of the Pinatubo volcano in July 1991, Geophys. Res. Lett., 19, 179182, 1992.

McCormick, M. P., Thomason, L. W., and Trepte, C. R.: Atmospheric effects of the Mt. Pinatubo eruption, Nature, 373, 399404, 1995.

McGill, M. J., Vaughan, M. A., Trepte, C. R., Hart, W. D., Hlavka, D. L., Winker, D. M., and Kuehn, R.: Airborne validation of spatial properties measured by the CALIPSO lidar, J. Geophys. Res., 112, D20201, doi:10.1029/2007JD008768, 2007.

Menke, W.: Geophysical Data Analysis: Discrete Inverse Theory. 260 pp., Academic Press, Orlando, 1984.

Miller, T. P. and Casadevall, T. J.: Volcanic hazards to aviation, in: Encyclopaedia of Volcanoes, edited by: Sigurdsson, H., Academic Press, San Diego, CA, 915.930, 2000.

Formation Flying: The Afternoon .A-Train" Satellite Constellation, NASA Fact sheet, FS-2003-1-053-GSFC, GSFC, Greenbelt, Maryland, USA, Available from: http://www.gsfc.nasa.gov, 2003.

Oberhuber, J. M., Herzog, M., Graf, H.-F., and Schwanke, K.: Volcanic plume simulation on large scales, J. Volcan. Geoth. Res., 87, 29-53, 1998.

Prata, A. J. and Bernardo, C.: Retrieval of volcanic $\mathrm{SO}_{2}$ column abundance from Atmospheric Infrared Sounder data, J. Geophys. Res., 112, D20204, doi:10.1029/2006JD007955, 2007.

Prata, A. J., Carn, S. A., Stohl, A., and Kerkmann, J.: Long range transport and fate of a stratospheric volcanic cloud from Soufriere Hills volcano, Montserrat, Atmos. Chem. Phys., 7, 5093-5103, 2007, http://www.atmos-chem-phys.net/7/5093/2007/.

Prata, A. J. and Kerkmann, J.: Simultaneous retrieval of volcanic ash and SO2 using MSG-SEVIRI measurements, Geophys. Res. Lett. 34, L05813, doi:10.1029/2006GL028691, 2007.

Prata, A. J., Rose, W. I., Self, S., and O’Brien, D. M.: Global, longterm sulphur dioxide measurements from TOVS data: A new tool for studying explosive volcanism and climate, Volcanism and the Earth's Atmosphere, Geophys. Monograph 139, AGU, 75-92, 2003.

Robock, A. and Oppenheimer, C.: Volcanism and the Earth's Atmosphere, Geophys. Monograph Series, 139, 364 pages, ISBN 0-87590-998-1, 2004.

Seibert, P.: Inverse modelling of sulfur emissions in Europe based on trajectories, In: Inverse Methods in; Global Biogeochemical Cycles, edited by: Kasibhatla, P., Heimann, M., Rayner, P., Mahowald, N., Prinn, R. G., and Hartley, D. E., 147-154, Geophysical Monograph 114, American Geophysical Union, ISBN 0-87590-097-6, 2000.

Seibert, P.: Inverse modelling with a Lagrangian particle dispersion model: application to point releases over limited time intervals, in: Air Pollution Modeling and its Application XIV, edited by: Schiermeier, F. A. and Gryning, S.-E., 381-389, Kluwer Academic Publ., 2001.
Stohl, A., Hittenberger, M., and Wotawa, G.: Validation of the Lagrangian particle dispersion model FLEXPART against large scale tracer experiment data, Atmos. Environ., 32, 4245-4264, 1998.

Stohl, A. and Thomson, D. J.: A density correction for Lagrangian particle dispersion models, Boundary-Layer Meteorol., 90, 155$167,1999$.

Stohl, A., Forster, C. Eckhardt, S., Spichtinger, N., Huntrieser, H., Heland, J., Schlager, H., Wilhelm, S., Arnold, F., and Cooper, O.: A backward modeling study of intercontinental pollution transport using aircraft measurements, J. Geophys. Res., 108, 4370, doi:10.1029/2002JD002862, 2003.

Stohl, A., Forster, C., Frank, A., Seibert, P., and Wotawa, G.: Technical note: The Lagrangian particle dispersion model FLEXPART version 6.2., Atmos. Chem. Phys., 5, 2461-2474, 2005, http://www.atmos-chem-phys.net/5/2461/2005/.

Stunder, B. J. B., Heffter, J. L., and Draxler, R. R.: Airborne volcanic ash forecast area reliability, Wea. Forecasting, 22, 11321139, 2007.

Textor, C., Graf, H. F., Herzog, M., and Oberhuber, J. M.: Injection of gases into the stratosphere by explosive volcanic eruptions, J. Geophys. Res., 108, 4606, doi:10.1029/2002JD002987, 2003.

Vaughan, M., Winker, D., and Powell, K.: CALIOP AlgorithmTheoretical Basis Document, part 2, Feature detection and layer properties algorithms, PC-SCI-202.01, NASA Langley Res. Cent., Hampton, Va. (Available at http://www-calipso.larc.nasa. gov/resources/project_documentation.php), 2005.

Wang, X., Boselli, A., D'Avino, L., Pisani, G., Spinelli, et al.: Volcanic dust characterization by EARLINET during Etna's eruptions in 2001-2002, Atmos. Environ., 42, 893-905, 2008.

Wesely, M. L. and Hicks, B. B.: Some factors that affect the deposition rates of sulfur dioxide and similar gases on vegetation. J. Air Poll. Contr. Assoc., 27, 1110-1116, 1977.

Wesely, M. L.: Parameterization of surface resistances to gaseous dry deposition in regional-scale numerical models, Atmos. Environ., 23, 1293-1304, 1989.

Winker, D. M, Pelon, J., and McCormick, M. P.: The CALIPSO mission: Spaceborne lidar for observation of aerosols and clouds, Proc. SPIE Int. Soc. Opt. Eng., 4893, 1.11, 2003.

Winker D. M., Hunt, W. H., and McGill, M. J: Initial performance assessment of CALIOP, Geophys. Res. Lett., 34, L19803, doi:10.1029/2007GL030135, 2007.

Yang, K., Krotkov, N. A., Krueger, A. J., Carn, S. A., Bhartia, P. K., and Levelt, P. F.: Retrieval of large volcanic $\mathrm{SO}_{2}$ columns from the Aura Ozone Monitoring Instrument: Comparison and limitations, J. Geophys. Res., 112, D24S43, doi: 10.1029/2007JD008825, 2007. 